\title{
Soft Devices for High-Resolution Neuro-Stimulation: The Interplay Between Low-Rigidity and Resolution
}

\author{
leva Vèbraité and Yael Hanein* \\ School of Electrical Engineering, Tel Aviv University, Tel Aviv, Israel
}

The field of neurostimulation has evolved over the last few decades from a crude, low-resolution approach to a highly sophisticated methodology entailing the use of state-of-the-art technologies. Neurostimulation has been tested for a growing number of neurological applications, demonstrating great promise and attracting growing attention in both academia and industry. Despite tremendous progress, long-term stability of the implants, their large dimensions, their rigidity and the methods of their introduction and anchoring to sensitive neural tissue remain challenging. The purpose of this review is to provide a concise introduction to the field of high-resolution neurostimulation from a technological perspective and to focus on opportunities stemming from developments

OPEN ACCESS

Edited by: Rylie A. Green,

Imperial College London, United Kingdom

Reviewed by:

Antoine Nonclercq,

Université Libre De Bruxelles, Belgium

Aaron D. Gilmour,

The University of Sydney, Australia

*Correspondence:

Yael Hanein

yaelha@tauex.tau.ac.il

Specialty section:

This article was submitted to Diagnostic and Therapeutic Devices,

a section of the journal

Frontiers in Medical Technology

Received: 03 March 2021

Accepted: 14 May 2021

Published: 14 June 2021

Citation:

Vèbraité I and Hanein Y (2021) Soft

Devices for High-Resolution

Neuro-Stimulation: The Interplay

Between Low-Rigidity and Resolution.

Front. Med. Technol. 3:675744.

doi: 10.3389/fmedt.2021.675744 in materials sciences and engineering to reduce device rigidity while optimizing electrode small dimensions. We discuss how these factors may contribute to smaller, lighter, softer and higher electrode density devices.

\section{Keywords: neurostimulation, prosthesis, electrode substrate, electrode adhesion, multi electrode arrays}

\section{INTRODUCTION}

Neuro stimulation is used in many medical technologies, with some devices already approved for clinical use. Since its early days, the field of neurostimulation developed hand-in-hand with advances in other fields. The adoption of emerging technologies, such as silicon micro-fabrication, wireless energy transfer, hermetic packaging, application-specific integrated circuit (ASIC) technology, flexible electronics and many more, assisted in the rapid development of the field. Despite great progress, the field has not yet reached a maturation stage. In particular, high-resolution with high flexibility is a major challenge and the exploration and testing of new materials and technologies is still ongoing. The field is also challenged by limited standardization. Many research laboratories use unique material preparation protocols, which may result with dramatically different properties for the "same" material. For example, thin film deposition parameters of TiN or IrOx (to name just two examples) can result with very different porosity and material stoichiometry leading to entirely different performances. In particular, electroplating, electrochemical etching, or coating electrode sites with conducting polymers can improve electrode performances (1-5). Another common example is polymer preparation details, which may induce dramatic changes in water absorbance (as one critically important example). A related challenging issue is the use of non-standard in-vitro and in-vivo tests, which are very common in academic investigations.

In this paper, we focus on high-resolution neuro-stimulation devices. We aim to highlight the considerations that influence material selection, and discuss how these factors presently limit 
device performances. We aim to emphasize the key role of different materials in facilitating high-resolution neural stimulation, along with reduced device dimensions and mechanical impact. We focus on three fundamental challenges in contemporary neurostimulation devices: substrate rigidity, electrode performance and device-tissue anchoring. In particular, we highlight the role of soft polymeric materials such as PDMS, polyimide, parylene, silk and shape memory polymers as substrate alternatives. Alternative electrode materials will also be reviewed. Finally, we discuss the electrode-tissue interface, focusing on rapid and long-term device anchoring, a critically important topic, yet the least investigated thus far. We use examples based on our own work experience to highlight workable solutions to some of the challenges we present in this paper. Many other aspects (such as low power ASIC design, energy transfer approaches and wireless communication) are not discussed as they go beyond the scope of this paper (6-9).

\section{Brief History of Implantable Electrodes}

Neurostimulation is an old practice, dating as far back as Volta's pioneering studies on electro-chemistry. Volta's efforts were followed with progressively deeper understanding of neuro-anatomy and function. In the 1930's, Hess implanted electrodes in the brain of cats, demonstrating efficacious neurostimulation. Amazingly, 70 years ago, Delgado used radio frequency-controlled wireless implanted neurostimulators in animals and humans (10). These pioneering studies were followed by refinements and improvements that resulted in highly miniaturized, multi-electrode and wireless systems.

Figure 1 shows four examples of neuro stimulation devices developed over the course of the last 70 years. Devices typically include active electrode sites, electrode wiring to electronic circuitry, electrical circuitry and modules for wireless communication.

In particular, silicon technology was recognized as an important enabling technology in neuronal interfacing in the late 1960's that offered excellent mechanical, electrical and later also optical properties. Wise and Najafi suggested the use of silicon technology to realize silicon shanks with highdensity microelectrode arrays suitable for local recording and stimulation of neurons $(15,16)$. This technology, commonly referred to as the Michigan probes, has been used extensively on rodents to study the fundamentals of neuronal circuits (1720). These devices were later further improved upon and can now boast amplification circuits (21). Norman at the University of Utah developed the Utah arrays, which consist of long and sharp penetrating silicon $(22,23)$. These arrays were used extensively for basic research but were also implanted in monkeys and humans (24-29). Beyond its electrical and mechanical properties, silicon also offers superb optical properties. This led to the interest of using silicon photo diodes in artificial retina devices (30). In the pioneering work of Chow and later improved by Zrenner, silicon photo diodes were implanted under the retina (31-34). Silicon photo diodes designed for the IR range were also demonstrated to be a highly effective method $(35,36)$.
Despite its many beneficial qualities, silicon is rigid (Young's modulus $150 \mathrm{GPa}$ ) compared with soft tissue (Young's modulus $0.4-15 \mathrm{kPa}$ ), which may cause substantial mechanical mismatch. Extensive investigations were directed in recent years to better understanding effects associated with this mismatch and developing novel soft interfaces with significantly lower mismatch and possibly better long-term performances. New electrode materials were also developed to improve device overall performances.

\section{Current Applications of Implantable Electrode Arrays}

Neural stimulation was applied to various applications including upper/lower limb prostheses, vagus nerve stimulation, deep brain stimulation (DBS) for Parkinson's disease, epilepsy, and depression, cochlear implants, and visual prostheses (37-39). With the exception of visual implants, these medical devices build on low-resolution technology (4-22 electrodes). The two domains where high-resolution stimulation appears to be of highest value is cochlear implants and visual prostheses. Contemporary cochlear implants still rely on low electrode density affecting the resolution of the delivered auditory signal. To achieve high quality auditory perception, higher resolution devices and alternative approaches are being explored (40). The retina is one of the most demanding neural tissue with which to interface. Accordingly, extensive research efforts are directed to this application. Retinal implants aim to restore vision in patients that suffer from retinal degenerative diseases that lead to blindness. Electrical stimulation of remaining neuronal layers in the retina leads to artificial perception of vision. Electronic devices are studied as an alternative to available pharmaceutical therapies and emerging gene therapy or stem cell transplantation. Some systems reached commercialization, such as the Argus II epiretinal device (Second Sight Medical Products, CA, USA), Alpha IMS subretinal device (Retinal Implant AG, Germany) and others in clinical trials, including PRIMA (Pixium Vision S.A., Paris, France) and NR600 (Nano Retina, Herzliya, Israel). A review of retinal implants history starting from 200 years ago when the first idea of an artificial vision evolved is available in Berényi et al. (19). Additional systematic reviews detailing recent advances in retinal prosthetic research can be found in (20-24).

High density will surely benefit cochlear and retinal implant but can benefit other applications that are presently limited to low resolution. Moreover, it can contribute to closed-loop operation, which is highly desired and can dramatically improve device operation.

\section{CORE CONSIDERATIONS}

The range of consideration affecting device performances is wide and includes: electrode size, packaging schemes, bio-compatibility, substrate flexibility, device stability in physiological conditions, duration of use, and local heating. Here we address those topics which relate most directly to our main focus. In particular, we discuss the electrode and substrate materials. For more related discussion on packaging, 

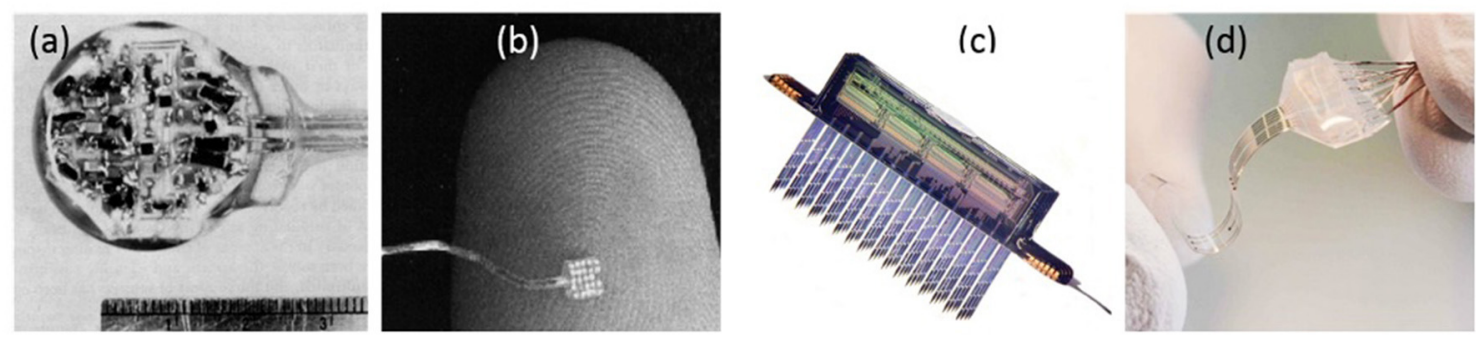

FIGURE 1 | Neurostimulation devices representing 70 years of progress. (a) Delgado's device with RF receiver and hermetic seal (11). (b) The artificial retina device by Liu et al. (12). (c) A 256-site 3D device for simultaneous recording and stimulation in the central nervous system (13). Picture Credit: Center for Wireless Integrated Microsystems, University of Michigan. (d) Spinal cord stimulation device with stretching ability (14). Copyright 2015, EPFL/Alain Herzog.

biocompatibility, and multi electrode array recordings we refer the interested readers to $(7,41-44)$ and references therein.

\section{Fundamentals of Neuro-Stimulation}

We begin with a concise explanation of neural stimulation and the core engineering considerations in designing and operating these devices. Neurons, the electrically active building block of the neural system, are primed to respond to external electrical stimulation. Under the appropriate conditions (i.e., amplitude, polarity, duration, frequency), neurons react to electric fields in their vicinity by firing action potentials in a manner closely resembling their response to natural neuronal signaling. The information that is then received by the brain can be controlled and guided to mimic natural processes.

Neural electrical stimulation harnesses voltage sensitive proteins in the cell membrane to illicit artificial neuronal activation (45). Generating an electrical potential at the vicinity of the electrode with a displacement current is considered safe and can be used for an extended duration without observed damage to the tissue or the electrodes (46). Stimulation pulses and their parameters must not damage the electrode or the tissue (47). Immune response, electrolysis of water, oxidation, corrosion or dissolution of the electrode could all be the result of irreversible faradaic processes (reduction and oxidation reactions at the electrode-electrolyte interface that result in new chemical species) $(48,49)$.

The distance between the electrode and the cell, as well as pulse features, affect stimulation efficacy and localization (50). Achieving localization is challenging, owing to variability in cell responsiveness to applied electric fields and how the electrode is coupled with the cells and their processes. To illustrate this point, Figure 1 shows an electrode with nearby cultured neurons and their activation probability at different stimulation amplitudes. The data show correlation between the stimulation amplitude and the number of activated neurons. Moreover, it is evident that some distant neurons are activated due to better coupling to the electrode by their neurites than neurons that are at much closer proximity.

In many applications, selective nerve activation is desired. Stimulation selectivity may be controlled by the amplitude of stimulation, but also by its pattern, width, inter-pulse width and frequency. A few examples in which these issues were studied are cuff electrode selective stimulation for sensory perception in humans, hd-TIME (high-density transverse intrafascicular multichannel electrode) electrode selective fiber activation in rats, and selective ON/OFF retinal ganglion cell stimulation (5153). Selectivity can be also enhanced by the reduced electrode size and increased density. These parameters are discussed below.

\section{Electrode Size and Resolution}

Each stimulating electrode has an effective stimulation range. In a simple model, this range can be considered as a uniform semihemisphere, which depends on the stimulation amplitude, tissue impedance and electrode area $(54,55)$. In reality, some cell types and regions are more sensitive than others, so an electrode may effectively stimulate distant cells while not affecting nearby units [see examples in Figure 2 (57)].

Reducing electrode size can also help in generating highdensity arrays and has been the focus of many investigations. The charge injection limit determines the amount of charge an electrode can deliver without crossing the water window limit. Minimal electrode size is determined by the charge injection limit of the electrode material so the amount of charge needed for stimulation can be reached. For example, Gzahavi studied sputtered iridium oxide (SIROF) electrode surface area and charge injection properties (58). An electrode with charge injection limit of $2.1 \mathrm{mC} / \mathrm{cm}^{2}$, would have to be $95 \mu \mathrm{m}^{2}$ in area to accommodate $2 \mathrm{nC}$ needed for stimulation. See Sekirnjak et al. (55) for some typical stimulation thresholds. To facilitate charge injection increase and electrode size reduction, the electrode surface area has to be increased through surface roughening or volume increase.

Many materials were studied in recent decades as electrode material. Among the most studied are platinum, iridium oxide and titanium nitride; a detailed review of electrode materials can be found here $(46,59,60)$. Some electrode-materials benefit from advantageous charge delivery capacity yet are challenged with poor compatibility with fabrication methods, in particular on soft substrates. One such example is carbon, which appears to be especially compatible for neurostimulation, yet suffers from poor compatibility with micro fabrication methods, for which reason alternative fabrication parameters and methods were investigated (61-66). Generally, metal thin films are notoriously unstable in vivo, suffering from dissolution, and delamination (67-71), 

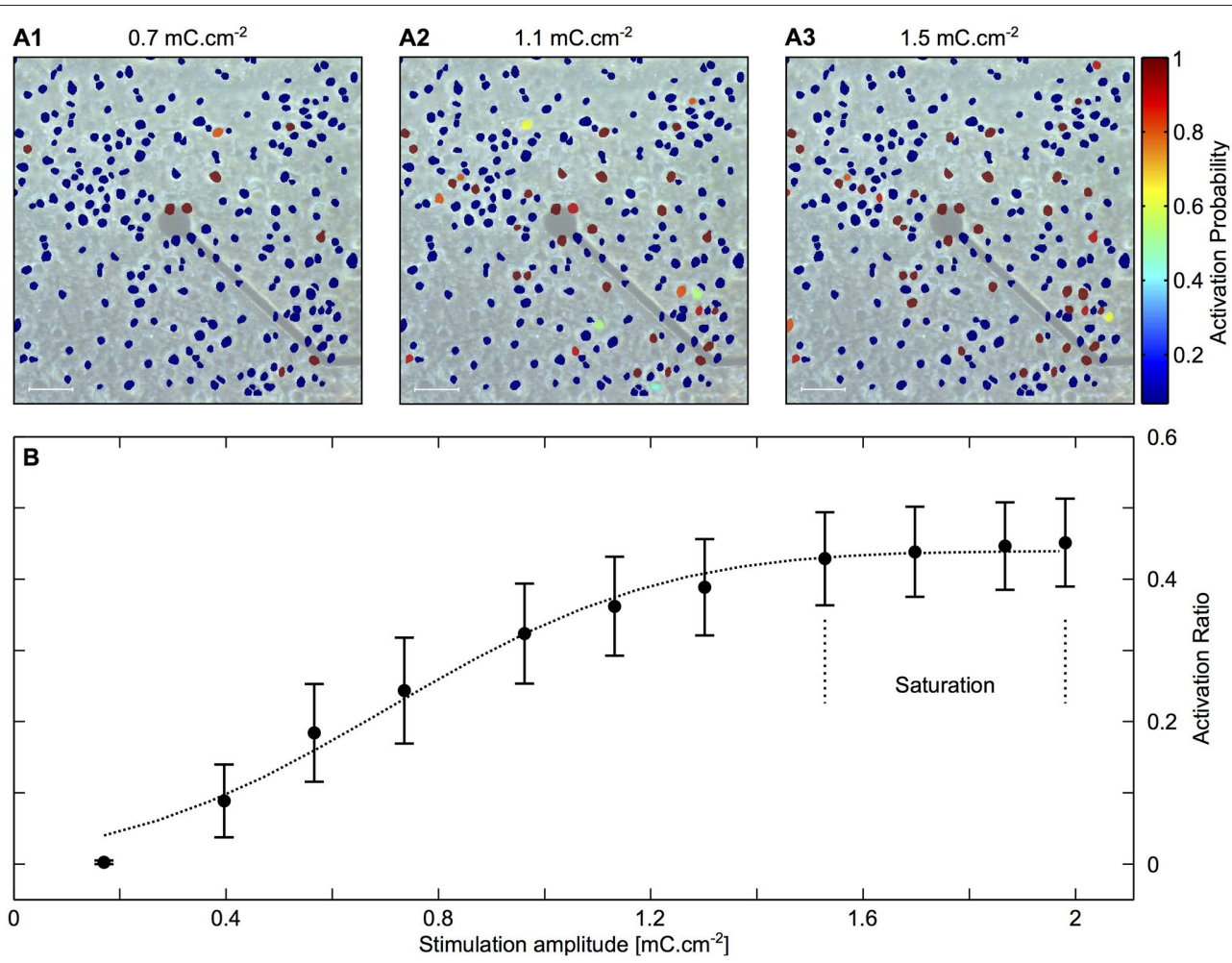

FIGURE 2 | Mapping activated neurons due to electrical stimulation amplitude and location. Cortical cultures were stimulated with rectangular and biphasic $400 \mu$ s long current pulses of 25-35 $\mu \mathrm{A}$ using MEA $30 \mu \mathrm{m}$ diameter electrodes. Neuronal action potentials evoked by an electrical stimulation were recorded and analyzed using $\mathrm{Ca} 2+$ imaging. (A1-A3) Color coded neuronal activation probability for three different stimulation amplitudes showing a correlation between stimulation amplitude and number of activated neurons. Scale bar: $50 \mu \mathrm{m}$. (B) Illustration of the latter observation showing proportion of activated neurons as a function of stimulation amplitude. The results indicate a saturation zone at which no further neurons are activated due to the distance of the electrode. Adapted from Wallach et al. (56). Copyright 2014, Wallach et al.

and stable electrode material compatible with soft substrates remains a challenge. On rigid substrates, such as silicon, excellent stimulation electrodes in the diameter range of $20 \mu \mathrm{m}$ can be realized (72). Electrode performances (both for recording and stimulation) on flexible substrate are generally inferior to those achieved on rigid substrates as the conditions required to form optimized films are less-favorable. This issue is further discussed at the concluding remarks of section Flexible Substrates.

It is important to note that thermal loading and heat dissipation should also be carefully considered in high-density applications and may limit the stimulation parameters, and consequently, the attained temporal and spatial resolution (73).

\section{Biocompatibilty}

Upon device insertion into the body and even before stimulation, the body responds through a series of reactions. Starting with acute inflammation, a release of reactive oxidative species (ROS), followed by possible chronic inflammation. Due to ROS attack and tissue regeneration processes, implant degradation and encapsulation, which affect long-term stability and efficacy of the device, may occur (41). Therefore, device materials must be biocompatible and withstand biological reactions. Biocompatibility requirements depend on expected operation duration and environment of intended use. Medical device biocompatibility should be evaluated according to the International Organization of Standardization (ISO) standardized tests (ISO 10993) (74). Implant for neural stimulation has to show no cytotoxicity, and foreign body reaction and glial encapsulation should be mild. Bulk and surface chemical properties of a device must be carefully evaluated to guarantee its biocompatibility and stability (75). Non-fouling coatings can render a material protection against protein adhesion in-vitro (42). In addition, sterilization method should be carefully chosen (76). Whichever sterilization approach is chosen (i.e., ethanol sterilization, autoclaving, UV radiation, ethylene oxide gas) should not damage the electrode mechanical or optical properties, nor accelerate corrosion, denaturation or delamination of packaging materials $(41,77)$.

\section{Flexibility and Substrate Stiffness}

The mechanical rigidity of neural interfaces is an extremely important property. Mechanical mismatch between the implant (Young's modulus 50-200 GPa) and the soft tissue (Young's modulus $0.2-15 \mathrm{kPa}$ ) may evoke an immune response, tissue scarring or trauma induced by implant placement or micromotion of the implant, and may explain electrode degradation 
and reduced stimulation efficacy over time (78-82). Moreover, poor implant-tissue adhesion, vascular damage, inflammation, electrode failure, and foreign body response can be linked with device rigidity and may lead to acute and chronic responses and electrode failure (83-86).

\section{Device Integrity}

Physiological conditions are aggressive and many materials and processes employed in the fabrication of neurostimulation devices, particularly in high-density device fabrication, poorly fit these conditions. Silicon based microfabricated and thin film processes are especially sensitive. Silicon and silicon dioxide have finite etching in physiological media (87). Stress is a major cause for failure and specially designed low-stress films had to be developed (88). Thin film deposition on polymers is particularly problematic owing to polymer swelling and films delamination.

Electrode stability under stimulation conditions is another major concern. The electrode-tissue interface is an electrochemical interface. In the presence of ionic solution, electrode properties are determined by the nature of the electro-chemical interface that forms (89). This interface determines some of the most important aspects in neuro-stimulation. Foremost is the charge transfer mechanism, which can range from purely a displacement current for non-Faradaic interface to a one involving charge transfer (Faradaic electrodes). The electro-chemical interface also determines the impedance of the electrodes, which in turn affects the thermal noise that is picked up by the electrode when used to record electrical activity (90, 91).

To guarantee that no faradaic processes are taking place, some studies emphasize the importance of a metal-oxide passive film formation on the electrode surface, electrode passivation, that would prevent electron transport across the interface $(48,59,90,91)$. Alternatively, non-faradaic electrodes can be used to minimize charge transfer across the electrode tissue interface (in such reactions, chemical species in the electrolyte are redistributed) $(92,93)$. To minimize electrochemical damage, a charge-balanced biphasic waveform must be used $(46,94$, 95). Other mechanisms, such as heating and electro-chemical reactions at the electrode interface, can lead to neuronal stimulation. These processes may damage the electrode or the tissue and are highly undesired. Therefore, optimal stimulation parameters, circuit passivation and device encapsulation are critical for safe stimulation, stability and biocompatibility of the device $(4,52,94,96)$.

\section{Acute vs. Chronic Devices and Hermetic Feedthroughs}

Medical device testing is performed ex vivo or in vivo lasting several days, few weeks and up to months and years. As mentioned before, body reaction to implants occurs at the time of surgery and implant placement is considered as acute phase and response. Long-term or chronic use of medical devices is mandatory in many clinical uses. The long-term performance of the electrodes, the insulation and the packaging performance must be evaluated (77) as well as the long-term hermetic bond of the electrical feed-through connections to the electrode array. The latter is an important challenge and requires special attention. For example, in Musk (97) parylene C coated titanium case was used along with flexible probes made of gold traces encapsulated in polyimide. Parylene C serves as a moisture barrier to ensure prolong functional lifetime. In Yin et al. (98) a titanium enclosure with 100 individual hermetic feed through pins were used. The wiring to the electrodes was overmolded with silicone to establish a barrier from the ionically conductive environment. Titanium enclosures are the gold standard in hermetic sealing but different approaches were considered as alternatives. Argus II implant components (i.e., coil, electrode array, scleral band) were insulated in silicone and reached a lifetime of 26 years (in accelerated testing) (99). Doped nanocrystalline diamond channels within polycrystalline diamond insulation were also suggested as a possible solution (100). More detailed discussion of the types of hermetic sealing methods, the challenges and advances as well as non-hermetic packaging can be found in $(9,101-104)$.

Accelerated aging tests and hermeticity testing performed in the early stages of device development provide valuable information regarding material suitability and longevity in harsh biological environments $(105,106)$. Overall, preclinical studies of medical device include: (1) Acute tests-to demonstrate device efficacy. (2) Chronic passive tests-to examine biological response to implant-tissue interface and material failure. Duration varies between 1 and 12 months and depends on properties of the electrode, its biocompatibility and interface with the tissue. (3) Chronic active tests are used to evaluate stimulation safety and efficacy. Testing focuses on histological and electrophysiological changes, electrode impedance stability and stimulation performance. Long-term evaluation of device safety with large animal models is advantageous since the anatomy, surgical procedure and environment is closer to that in the clinical use (77).

\section{Device Anchoring}

Neurostimulating devices are becoming ever more flexible, yet the electrode-tissue anchoring remains a challenge. In many reported cases, implants are mechanically attached to the soft tissue (by penetrating the tissue) or secured with sutures and/or metal tacks (107). The latter is a mature method and offers great attachment strength, but is problematic with delicate tissue, such as the retina. Even when the implant itself shows great biocompatibility, sutures and tacks can lead to postsurgical adverse effects, such as dislodging, tissue scarring and inflammation or gliosis, which may lead to reduced device function (107-111). Long-term studies found that a poorly secured implant leads to increased distance between the tissue and the electrodes, including sub-threshold stimulation (107, 112). Therefore, alternative device anchoring methods are investigated and few strategies discussed in section Device Anchoring Mechanisms and Support Materials.

\section{Multi Electrode Arrays}

The use of micro-fabrication techniques in neuro-stimulation devices paved the way for the extensive use of multi electrode arrays (MEA) so that multiple electrodes can be simultaneously 
used to record and stimulate neurons. In many applications, the ability to perform both recording and stimulation at the same time and in close proximity to each other holds promise for closed loop control. The recorded signal can be used to assess the efficacy of the stimulation, which in turn can be modified to achieve a desired response (113). For example, in DBS, closed loop strategies aim to achieve higher efficiencies and possibly fewer side effects (114). Recently, Ferleger et al. demonstrated a fully implanted closed-loop DBS system for essential tremor treatment (115). High density recording may also help in source localization and noise reduction.

Having established the core considerations in designing neuro-stimulation devices, we now turn to discuss different strategies to implement flexible substrates along with high quality electrodes.

\section{FLEXIBLE SUBSTRATES}

The realization that the mechanical mismatch between a rigid implant and a soft neural tissue is a major factor that restricts the long-term stability of the implant led to an increased interest in soft materials (116-122). Materials such as polyimide (PI), polydimethylsiloxane (PDMS), parylene $\mathrm{C}$ and shape memory polymers (SMPs) (Figure 3) have significantly lower Young's modulus than silicon, hence they are gaining increased interest and are recognized as preferred substrate materials for resolving the mechanical tissue-electrode mismatch $(123,124)$. In addition, new materials were proposed to also substitute rigid electrode materials. Nano materials such as graphenes, carbon nanotubes and nanowires can be implemented on flexible substrates and offer marked advantages. For instance, specific capacitance values may improve from $4.5 \cdot 10^{-6} \mathrm{mFcm}^{-2}$ (Pt electrodes coated with SWCNT on a rigid Pyrex substrate) to $2 \mathrm{mFcm}^{-2}$ (CNT on a flexible MEA) (125). These materials offer compatibility with flexible substrates along with high surface roughness and reduced impedance comparing to uncoated or gold-coated electrodes $(66,126,127)$. In this section, we review soft materials used primarily as substrate materials, focusing on PDMS, polyimide, parylene C, silk fibroin and SMP separately.

\section{PDMS}

Polydimethylsiloxane (PDMS), a type of silicone elastomer, has excellent mechanical properties, it is clinically approved as USP class VI and is used widely in various implants (118). It has high permeability to gases, impermeability to ions, along with optical transparency. Moreover, it has $\mathrm{M} \Omega \cdot \mathrm{cm}$ resistance in its wet state $(67,128)$. With Young's modulus of $1.8 \mathrm{MPa}$ and the ability to be formed into thin films $(10-100 \mu \mathrm{m})$, it was studied for chronically implantable devices (67). It was used as a substrate and encapsulation material in cochlear, bladder and pain controllers, to reduce the mechanical mismatch between the tissue and the device (124). For instance, when used as a substrate for peripheral nerve stimulation, it conformally wraps around the nerve and achieves a stable interface (129). EDura electrodes, with PDMS as a substrate, exhibit restored locomotion after spinal injury (120). Ferlauto et al. designed a foldable photovoltaic epiretinal prosthesis using PDMS in the shape of a dome to match the curvature of the eye (130). Hybrid electrodes for subdural neural recording and stimulation, where the electrode is based on PDMS and parylene bilayer, allowed easy handling and integration of electrodes (131). PDMS is also successfully used for electrode encapsulation for cortical stimulation and recording electrodes evoking fore- and hindmotor outputs (132). Tybrandt reported a novel inert high performance, stretchable electrode grid (SEG) for somatosensory cortex recordings. Such a device consists of $\mathrm{Au}-\mathrm{TiO}_{2}$ nanowires with PDMS serving as substrate as well as encapsulation material (20). Despite its many advantageous properties, PDMS porosity is associated with swelling in wet environment which can lead to metal layer delamination, poor metal adhesion and relatively limited insulating performances (67, 131, 133, 134). In particular, metal adhesion to PDMS requires special treatment to promote stable bonding (131). Its porosity and permeability to gasses and water was recognized in the microfluidic community as a severe challenge and motivated studies on how to combine PDMS with other thin films without affecting its superior mechanical properties. Parylene incorporation onto PDMS suppressed water absorption and limited small molecule permeability, thus increasing its lifetime dramatically $(135,136)$. Several studies in the field of neuro-stimulation note that PDMS should be used with caution, even suggesting the use parylene $\mathrm{C}$ as a barrier or by incorporating rigid platforms below the electrodes to avoid cracks $(130,132,137)$. Altogether, PDMS present use in neuro-stimulation devices is restricted to relatively thick films $>60 \mu \mathrm{m}$, and relatively large electrodes (see Figure 4).

\section{Polyimide}

Polyimide (PI) is an alternative flexible material extensively studied for biomedical applications. It is a polymer of imide monomers $\left(\mathrm{CO}-\mathrm{NR}_{2}\right)$ (Figure 3). It has been used as passivation or insulation for more than 40 years due to its excellent resistance to chemical agents, biocompatibility, low moisture absorption, high thermal stability and flexibility (Young's modulus of 1.5$3 \mathrm{GPa})(118,144)$. Moreover, PI is compatible with standard photolithography and can be fabricated in various designs, at low thicknesses $(1-15 \mu \mathrm{m})(145,146)$. Polyimides are very common in neuronal interfacing devices $(67,144,145$, $147,148)$. Investigation into biomedical applications focused mostly on one variant, PI-2611, that consists of biphenyl dianhydride (BPDA) and p-phenilene diamine (PPD) for their better biocompatibility and lower moisture absorption (148150). Some neuro-stimulation devices with polyimide substrate are in clinical trials or have already been approved as safe. Retinal implant Argus II by Second Sight Ltd used polyimide as a substrate and was recently adapted for cortical stimulation (implant called Orion) (151, 152). Very recently, Neuralink announced PI-based probes for multi-site recording and stimulation from freely behaving animals for BMI applications (97). Electrodes with PI as substrate and insulating material were developed for the peripheral nervous system. Device design included sieve and cuff electrodes, and longitudinal and transverse intra-fascicular multichannel electrodes (LIFE and TIME, respectively), to achieve basic motor functions restoration (148, 149, 153-155). Various coatings like maltose, silk and 


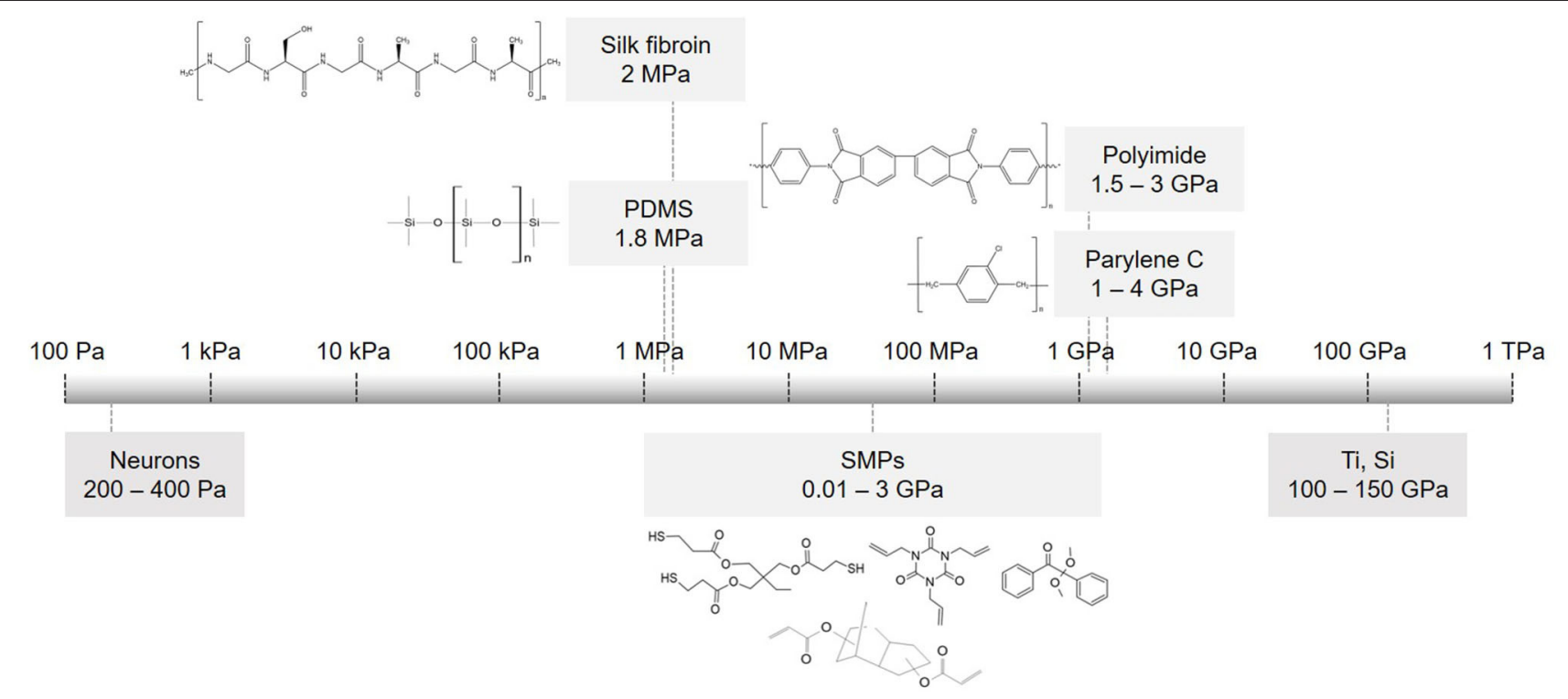

FIGURE 3 | Flexible substrate materials used in implantable devices. Scale of elastic modulus for commonly used substrates and their chemical structures: PDMS, parylene C, polyimide PI 2611, silk fibroin and monomers used to make thiol-ene acrylate polymer (SMP).

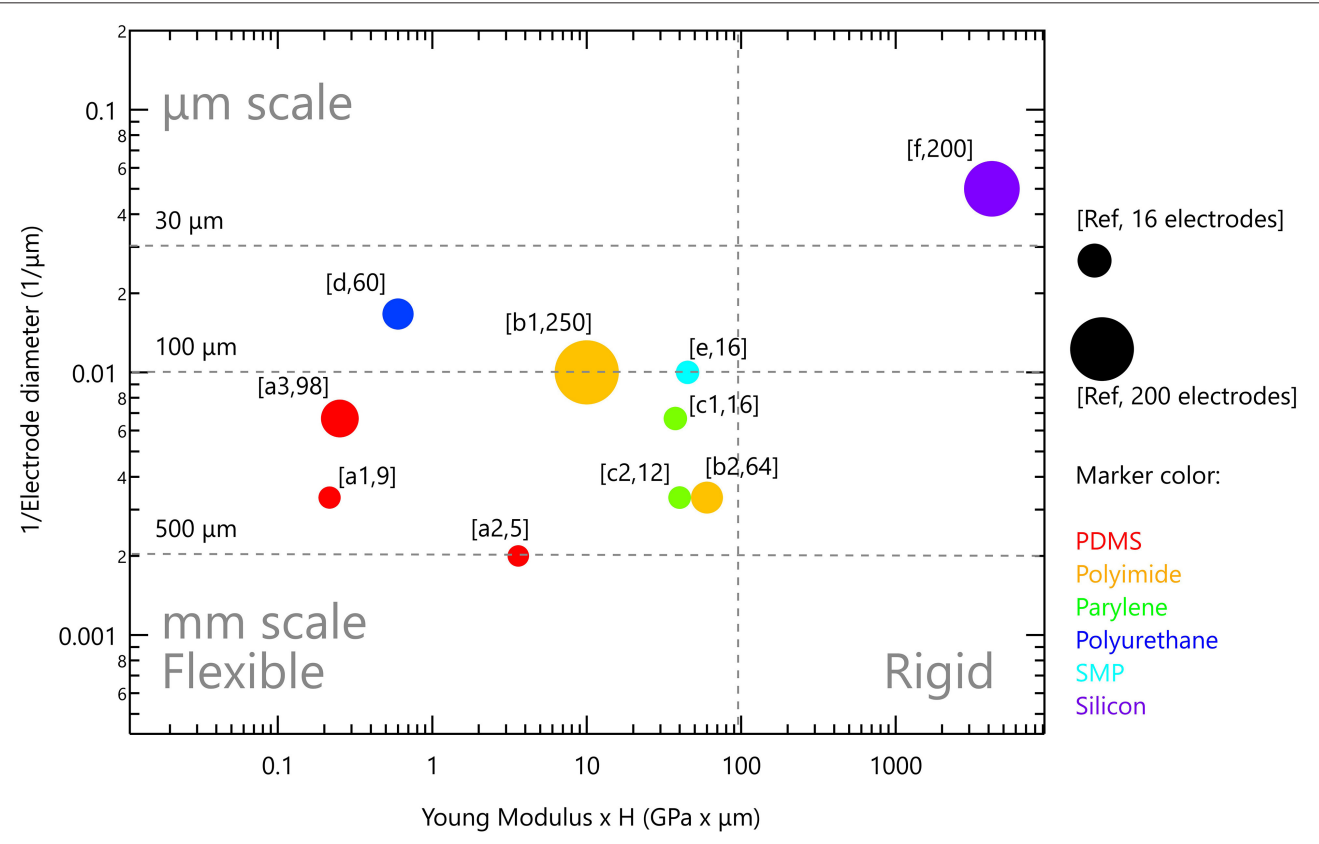

FIGURE 4 | Rigid and flexible neurostimulation devices. Vertical scale is the inverse of electrode diameter; horizontal scale is Young modulus multiplied by device thickness. Marker size reflects the number of electrodes in the device. References: (PDMS) a1 (120), a2 (132), a3 (137); (polyimide) b1 (138), b2 (139); (parylene) c1 (140), c2 (141); (polyurethane) d (142); (SMP) e (143); (silicon) f (36).

polyethylene glycol were investigated to temporarily stiffen the implant during tissue penetration (156-159). Polyimide is indeed a promising material for chronic, neuro-stimulation, at least with the use of thin film electrode methods and materials, yet high-density is still limited, probably by modest electrode performances.

\section{Parylene C}

Parylene [poly(dichloro-p-xylylene)] C, is a favorable material for encapsulation due to its insulating properties and biocompatibility (FDA approved as USP class VI biocompatible material). Parylene $\mathrm{C}$ has low water permeability and moisture absorption of $0.06 \%$. Moreover, it exhibits a low dielectric 
constant and loss factor; hence, it provides effective electric isolation. Parylene $\mathrm{C}$ can form conformal coatings as thin as hundreds of $\mathrm{nm}$ to $\sim 100 \mu \mathrm{m}$. Young's modulus of $1-4$ GPa ensures flexibility and minimizes tissue-device mechanical mismatch $(67,118,160)$. Parylene was used in polyimide-based retinal prosthesis as an insulating material to improve device durability $(112,138)$.

Parylene is used also as a substrate material in several applications. It was shown that parylene-based implants are robust under surgical conditions and deliver efficient stimulation in in vivo testing (140, 161-163). Parylene is used as both substrate and insulating material for cochlear implants and cortical stimulation (141, 164). Minnikanti et al. (165) performed a comprehensive study to examine parylene $\mathrm{C}$ long-term stability, demonstrating that $\mathrm{Al}_{2} \mathrm{O}_{3}$ coating significantly enhances insulation properties and improves lifetime of neural interfaces for chronic implantation (166). Nevertheless, Oliva stresses that even though parylene C boasts excellent characteristics, specific long term biocompatibility studies must be performed for each implanted tissue (167). Moreover, parylene is susceptible to oxidation at temperatures higher than $100^{\circ} \mathrm{C}$ and micromachining can cause cracks, burns or wrinkles. Parylene has poor adhesion to metals, in some cases resulting in delamination and device failure in wet conditions. Post-processing techniques, such as vacuum annealing, plasma treatment, use of adhesion promoter Silane A-174, and nanostructuring the metal surface, can increase long-term stability and adhesion $(76,160,161,168)$.

\section{Shape Memory Polymers}

Shape memory polymers (SMPs) are considered to be smart materials because of their unique ability to temporarily alter and recover their shape upon specific external stimuli, such as heat, electric field, magnetic field, or irradiation (169). As of yet, the most common group of SMPs are thermally induced SMPs, whose change in shape is initiated by a change in temperature. Such a change is the combined result of molecular polymers' network structure as well as certain programming and processing technologies. Detailed explanations of working mechanisms and shape memory phenomena can be found in (169-171). SMPs exhibit a wide Young's modulus range of $0.01-3 \mathrm{GPa}$, low density, low cytotoxicity, potential biocompatibility and biodegradability; thus, they were proposed for medical use about 20 years ago. Since then, their use and development has been continually active and growing at a rapid rate (172-174). SMPs are candidates for various medical applications from sutures to stents, from drug delivery methods to neuronal probes (175-177).

SMPs as a substrate for neural recording and stimulating electrodes were first proposed and most investigated by Voits et al. Their team reported that thiol-ene/acrylate SMPs (Figure 3) are as rigid as polyimides (about 1-2 GPa) during insertion and soften by two orders of magnitude (to $\sim 50-20 \mathrm{MPa}$ ) upon exposure to physiological conditions $(178,179)$. They further demonstrated that these SMPs are compatible with photolithoghraphy, in wet environments take up $<3 \%$ fluid, and give stable recordings in vivo for 2 months. Thiolene/acrylate SMPs showed no cytotoxicity nor neurotoxicity, and reduced the foreign body response (180). Thin film softening cuffs or spinal cord stimulation arrays provide optimal nerve-electrode interface and selective stimulation with stable long-term performance in vivo $(143,181)$. Recently, a highdensity microelectrode array for retinal stimulation on SMP was developed. Upon insertion, it conforms with the eye shape (182). Zhang et al. developed 3D twinning electrodes for vagus nerve and sciatic nerve stimulation. Inside the body (at $37^{\circ} \mathrm{C}$ ), the elastic modulus of the implant changes from $100 \mathrm{MPa}$ to $300 \mathrm{kPa}$, it recovers the shape naturally and self-climbs onto the nerves to form a flexible $3 \mathrm{D}$ neural interface $(183,184)$. Compared with polyimide or parylene-C, SMPs offer reduced tissue-electrode mechanical mismatch, allowing better signal to noise ratio and reduction in stimulation thresholds. Long-term stability, robustness and device interlayer adhesion are still to be investigated (185).

\section{Silk}

Silk fibroin is a biopolymer purified from Bombyx mori silkworm cocoons. The amino acid sequence of silk fibroin contains repetitive glycine-alanine-glycine-alanine-glycine-serine (GAGAGS) repeats, which self-assemble into an antiparallel b-sheet structure that gives the silk-based materials high mechanical strength (186). Silk has been used as a suture material for centuries. It can be formed into films, fibers, gels, porous scaffolds, powders, and microspheres (187-189). Silk films are non-immunogenic, mechanically flexible, show great surface quality and have optical transparency and controllable degradation rate (188-190). Furthermore, silk fibroin was shown to exhibit excellent electrical insulating properties, for which reason it is often chosen as the gate dielectric in organic thin-film transistors (191-195). Depending on application, silk films can be patterned with controllable thickness and porosity, and chemically modified with growth or adhesion factors.

Biodegradable polymeric materials such as silk gained a lot of interest, owing to their easy implantation and biodegradability. The degradation rate decreases with an increase in B-sheet content or chemical modification. These properties depend on the implantation site and the mechanical environment (196200). Silk fibroin is a polymer candidate for tissue engineering and implantable devices (186). Rogers et al. presented gold electrode arrays for brain stimulation, with polyimide as an electrode substrate supported with degradable silk fibroin. Silk enabled conformal wrapping of the array to the brain surface (201). A parylene probe embedded in the silk to stiffen the probe for insertion into the motor cortex was also reported (202). Hronik-Tupoij et al. used silk as a substrate, and showed that electrical stimulation induced axon growth and alignment, which is critically important for peripheral nerve regeneration applications (203). A fully organic implant based on silk was demonstrated for retinal stimulation. Silk served as a substrate and photoactive conjugated polymers as a functional component (204). Silk-based flexible electrode arrays were shown to be used for localized recording and stimulation in vivo (205). It is indeed an attractive material in biomedical applications and is in particular preferred as sacrificial material for device insertion 
TABLE 1 | A comparison between different flexible materials used as electrode array substrates.

\begin{tabular}{|c|c|c|c|c|c|c|c|c|c|}
\hline Material & $\begin{array}{c}\text { Young's } \\
\text { modulus } \\
\text { (GPa) }\end{array}$ & $\begin{array}{c}\text { Moisture } \\
\text { absorption } \\
(\%)\end{array}$ & $\begin{array}{l}\text { Diffusion } \\
\text { coefficient } \\
\left(\mathrm{m}^{2} / \mathrm{s}\right)\end{array}$ & $\begin{array}{c}\text { Specific } \\
\text { resistivity } \\
(\Omega \cdot \mathrm{cm})\end{array}$ & $\begin{array}{l}\text { Dielectric } \\
\text { Constant }\end{array}$ & $\begin{array}{c}\text { Typical } \\
\text { thickness } \\
(\mu \mathrm{m})\end{array}$ & $\begin{array}{l}\text { Typical test } \\
\text { duration in } \\
\text { vivo (weeks) }\end{array}$ & \multicolumn{2}{|c|}{ Regulatory } \\
\hline $\begin{array}{l}\text { SMP } \\
(174,178)\end{array}$ & $0.01-3$ & $<3$ & NA & $10^{14}$ & NA & 30-100 & NA & $\begin{array}{l}\text { Many tested } \\
\text { according ISO } \\
10993-5 \text { (185) }\end{array}$ & $\begin{array}{l}\text { For blocking blood } \\
\text { flow }\end{array}$ \\
\hline Silk (213) & 0.02 & NA & NA & NA & 6.1 & 30 & 24 & & $\begin{array}{l}\text { Sutures, Scaffolds, } \\
\text { drug delivery } \\
\text { platforms }\end{array}$ \\
\hline Polyimide (67) & $1.3-3$ & 0.5 & $\begin{array}{c}1.1^{*} 10^{-10} \\
(214)\end{array}$ & $10^{16}$ & 2.9 & $7-20$ & $2-72$ & $\begin{array}{l}\text { "Comply with, but } \\
\text { not ISO certified." } \\
\text { (150) }\end{array}$ & $\begin{array}{l}\text { Retinal, Cortical } \\
\text { implants, } \\
\text { Pacemakers, } \\
\text { catheters }\end{array}$ \\
\hline $\begin{array}{l}\text { Parylene C } \\
\text { (67) }\end{array}$ & $1-4$ & 0.06 & $\begin{array}{c}2.6^{*} 10^{-13} \\
(206)\end{array}$ & $10^{12}-10^{16}$ & $2.95-3.15$ & $6-20$ & 12 & $\begin{array}{l}\text { VSi: USP Class VI, } \\
\text { ISO } 109934-6 \text {, } \\
10-11(215)\end{array}$ & Coating material \\
\hline
\end{tabular}

References mentioned in the table are those that provide the most detailed information related to the addressed properties.

into the tissue. However, despite its benefits, its suitability for long-term use is limited.

Table 1 summarizes the main properties of the different substrate materials described above. Indeed, PDMS has markedly low Young's Modulus (E), yet owing to its porosity, it is used in neural stimulation applications as a thick substrate. Accordingly, its effective stiffness $\left(\mathrm{EHd}^{3} / 4 \mathrm{~L}^{3}\right.$ for a film with a length $\mathrm{L}$, thickness $\mathrm{H}$, width $\mathrm{d}$ and Young's modulus $\mathrm{E}$ ) is only an order of magnitude lower than a thin parylene C. Heo et al. compared water evaporation through $8 \mathrm{~mm}$-thick PDMS to $2.5 \mu \mathrm{m}$ parylene C films (206). Because PDMS has a much higher diffusion coefficient of water $\left(2 \times 10^{-9} \mathrm{~m}^{2} / \mathrm{s}\right)$ than parylene $\left(2.6 \times 10^{-13} \mathrm{~m}^{2} / \mathrm{s}\right)$, polyimide and polyurethane, a much thicker PDMS is usually used in devices. Surface modification schemes may improve PDMS stability, but these coatings have to be validated in vivo. Presently, polyimide is the most studied material showing relative long-term stability in vivo. Flexible polymers are inherently prone to cracks and water absorption and any polymer based neural stimulation system will have to be carefully validated. Implant stiffness and thickness deserve attention as these features depend on the insertion process, the implantation site and the duration of the intended use (shortor long-term). Moreover, it is preferable to choose materials that are USP or ISO 10993 approved. Nevertheless, since each device is unique, each research group should still perform biocompatibility, stability, and efficacy tests of the intermediate and final device.

Figure 4 presents the flexible neurostimulation devices we reviewed in this paper and have been tested in-vivo. Each device is plotted with the inverse of electrode diameter as the vertical scale and Young modulus multiplied by device thickness as the horizontal scale. Marker size reflects the number of electrodes in the device. It is clear that contemporary flexible devices have reduced electrode performances. Soft devices with $\mu \mathrm{m}$ scale electrodes, such as those available for silicon-based devices, are not yet available. It is our aim to highlight this gap, and to discuss possible directions to address it. Two strategies are discussed below: (1) Improved device anchoring to achieve better electrode-tissue coupling and (2) Improved electrode technology which will increase electrode charge injection limit and will lead to the ability to form smaller and more stable electrodes. 


\section{DEVICE ANCHORING MECHANISMS AND SUPPORT MATERIALS}

Several strategies are commonly applied to anchor and stabilize devices into a tissue and were discussed in section Device Anchoring. Here, we discuss the idea of ideal adhesive for device anchoring to the tissue and alternative methods to sutures and tacks.

An ideal adhesive will allow: (1) rapid anchoring; (2) strong attachment; (3) long-term stability, non-inflammatory and nontoxicity. Various hydrogels, such as cellulose, alginate, polyvinyl alcohol or polyethylene glycol were proposed in recent years (216). Alternatively, high-surface area materials were shown to enhance the interaction with the tissue. Carbon nanotubes, in particular, have higher surface area and strong cell-electrode coupling $(95,217)$. Implants with apertures, allowing cell migration and anchoring of the tissue at close proximity to the electrodes were also studied (73). These solutions can improve tissue-electrode interface over time, but do not provide the rapid anchoring needed.

Bio-adhesives, such as cyanoacrylate and fibrin glue, are used to close leaking sclerotomies, to treat corneal perforations, to secure the retina after detachment, and to seal wounds. These glues offer easy application with the setting time lasting from $10 \mathrm{~s}$ to $2 \mathrm{~min}$ (218). However, the use of these bio-adhesives may result in complications such as incomplete closure, foreign body response, and viral infection. The main downside of fibrin glue includes low adhesive strength and limitation to biological implants, while cyanoacrylate offers a strong bond and adhesion to non-biological materials. Yet, under some conditions, it can be toxic and cause inflammation (109).

$\mathrm{N}$-isopropyl acrylamide (NIPAM) is yet another promising bioadhesive material for implants. NIPAM is a thermoresponsive polymer that exhibits a lower critical solution temperature (LCST) of about $32^{\circ} \mathrm{C}$. Below LCST, NIPAM is hydrophilic and soluble, while above LCST, it becomes a hydrophobic and viscous gel with strong adhesion to tissue. As this process is reversible, NIPAM exhibits a great advantage over other bioadhesive materials. An investigation into NIPAM properties for tissue engineering purposes, cell proliferation and adhesion, drug delivery, and intra-vitreal injections demonstrated that it is non-toxic and safe (219221). In a comprehensive cytotoxicity study, it was shown that pNIPAM-coated surfaces are not cytotoxic, while NIPAM monomer in pure powdered form is. Thus, it was stressed that device viability depends on the purity of the polymer and the deposition type (222). pNIPAM in a liquid form was used in rabbits to close scleral wounds and resulted in effective wound healing with no abnormalities or inflammatory reactions (223). It was also studied in vivo in rabbit eyes for over 6 weeks. Flexible implants made of parylene C and PDMS were coated with NIPAM by plasma deposition. Once the implant was placed next to the retina, the implant was gently pressed on the retina for 15-20 s. Immediate adhesion was observed and a 6-week follow-up revealed no retinal tears nor occurrence of retinal detachment (224).
Bio-inspired materials exhibit interesting adhesive properties. The use of an active form of Vitamin B2 (riboflavin-5-phosphate) for photochemical tissue bonding showed impressive results in ocular surgery. Unfortunately, it is not suitable for anchoring devices to the retina due to ultraviolet light required to activate the bonding procedure $(109,225,226)$. Other sources for bioinspired adhesives come from marine animals, such as mussels and sandcastle worms (227-229). Spider silk is yet another material representing one of the strongest natural fibers that boasts adhesive strength in wet environments (230-232). Spider silk glues well to wood, plastics, silicone, and can be used in biomedical applications $(233,234)$. Cell adhesion peptides such as RGD motifs also improve device-tissue adhesion, yet will not support rapid anchoring $(235,236)$. Even though materials like NIPAM, RGD motifs or bio-adhesives are promising alternatives for improved anchoring, their use in neuro-stimulation devices requires further investigation.

Another important aspect that needs to be considered is implant insertion to the target tissue. Reducing the rigidity of the electrodes and loss of device stiffness makes tissue penetration challenging. This applies to applications where electrodes have to penetrate brain tissue. Various coatings like maltose, silk and polyethylene glycol (PEG) were investigated to temporarily stiffen the implant during the penetration (156-159). Another approach is the use of a guide such as a rigid shuttle device $(237,238)$. Apollo et al. reviewed the most recent innovations in flexible neural electrode insertion approaches, including Tyrosine-derived terpolymer, poly (vinyl alcohol) (PVA) and poly (lactic-co-glycolic acid) (PLGA), microactuation, and magnetic and bioinspired surgical implantation strategies (239).

\section{ELECTRODE MATERIALS}

The conventional electrode materials, which have been shown to work very well on rigid substrates, have to be carefully optimized to reach similar performances on flexible and soft materials, specifically, the impedance and charge injection limit. Challengingly, data regarding these values is not always reported. Several emerging solutions were suggested in recent years, four of which are discussed below.

\section{CNTs}

Nano materials offer an interesting alternative to the more conventional materials. Nano electrodes with increased roughness, using nanowires, graphene, conductive polymers or carbon nanotube (CNT) coatings can resolve long-standing challenges $(95,216,240)$. In particular, carbon nanotubes $(241,242)$ which exhibit Young's Modulus as high as $1 \mathrm{TPa}$ and tensile strength of $100 \mathrm{GPa}$, can bend and twist without breaking, and are therefore an appealing material for stable, thin and flexible electrodes (243-245). CNTs are known for their utility in recording neuronal signaling, demonstrating reduced impedance and much higher signal to noise ratio $(156,217,246-248)$. The in vivo biocompatibility of CNTs and other carbon materials was addressed by Baldrihi and Veronica, concluding that it strongly depends on the administration site, dosage, purity, 
and agglomeration $(241,242,245)$. In 2005 , it was shown that CNTs can be used for neuronal signal improvement and enhanced dendrite elongation as well as cell adhesion and growth $(217,249,250)$. This was followed by a first demonstration of in vitro stimulation of neurons with CNT electrodes (243). One of the significant advantages of CNT electrodes is their electrical and mechanical interface with neurons. Their tridimensional structure and high surface area increases electrode capacitance, lowers the impedance, therefore enabling size reduction of the electrodes to achieve high density devices with high efficacy local stimulation, and reduces the tissue inflammatory response $(240,242,251-253)$. Vitale et al. demonstrated neural recording and stimulation using CNT fiber electrodes, when neurons in vivo were activated as efficiently as metal electrodes with a 10 times larger surface area (254). Direct electrical stimulation of neurons by using CNT electrodes was presented by several groups $(126,253,255)$, as well as extracellular stimulation using CNT MEAs (126, 243, 256-258). David-Pur et al. presented a completely flexible micro-electrode device based on various flexible substrates (PDMS, adhesive medical tape, parylene C and polyimide shown in Figure 5B) with MWCNT traces and stimulating electrodes for high efficacy neuronal stimulation $(125,259,260)$. The general fabrication process is described in Figure 5A. The extraordinary strength, flexibility, surface morphology, and electrical conductivity of CNTs make them a strong candidate for neuronal interfacing in small, high-charge density and low-impedance flexible microelectronic devices. CNT-based electrodes exhibit some of the best electro-chemical performances, yet their fabrication process is non-standard and incompatible with conventional fabrication approaches. Adoption of this technology will require process automation.

\section{Conducting Polymers (CPs) Hydrogels (CPHs) and Elastomers (CEs)}

Conductive polymers (CPs) are organic polymers possessing high electrical conductivity, mechanical softness, biocompatibility and easy surface modification. Thus, they are widely used as electrode coating materials in biomedical applications (261). Most common CPs used for neural interfacing electrodes include polypyrrole (PPy), poly(aniline) (PANI), polythiophene (PTh) and poly(ethylene dioxythio- phene) (PEDOT) $(216,262,263)$. The oxidized polymer carrying a positive charge are typically doped with negatively charged counter-ions, such as poly(styrene sulfonate) (PSS) or paratoluene sulphonate (pTS) and other variations. Such CP coatings of electrode sites increase charge storage capacity, provide low impedance and high charge injection limit, thus improving tissue stimulation. Nevertheless, many reports still raise concerns about its mechanical stability in chronic implantation (264).

Studies proposed combinations of CPs and elastomers, CPs and hydrogels or CPs and CNT composites. Conducting polymer hydrogels (CPHs) result in softer films (Young's modulus of $2 \mathrm{MPa}$ ) while maintaining $\mathrm{CP}$ electrical properties. Another advantage of $\mathrm{CPHs}$ is its surface hydrophilicity compared to CPs (265). Need to note that with hydrogels introduce porosity and swelling, thus degree of cross-linking has to be chosen carefully.
Reviews discussing chemical properties, fabrication processes, challenges and future perspectives can be found $(266,267)$. Integration of $\mathrm{CPs}$ with elastomers such as polyurethane (PU) or PDMS yield conductive elastomers (CEs). Such combinations as in CPHs maintain electrical performance of CPs and provide mechanical elasticity (142). Du et al. demonstrated that ultrasoft CE micro-wires (Young's modulus lower than $1 \mathrm{MPa}$ ) reduced inflammatory response and caused less distortion in an 8-week implantation period compared to tungsten electrodes (268). Also, 1 month post-implantation results showed reduced macrophage activation compared to PI implants (269). Ferrari et al. presented all polymer printed nerve cuff electrode with five PEDOT:PSS with $10 \%$ glycerol electrodes (at the final area of $\left.130 \times 130 \mu \mathrm{m}^{2}\right)(270)$. Yuk et al. demonstrated capability to print nine PEDOT:PSS electrodes $30 \mu \mathrm{m}$ in diameter for in vivo recording of neural activities (271). Combination of CPs with other semiconducting materials such as poly(3-hexylthiophene) (P3HT) was shown to be able successfully stimulate retina up to several months (204). Nevertheless, open challenges in using these materials in high-resolution neurostimulation include their long-term stability and their ability to form high-resolution patterns with existing approaches.

\section{Opto-Electrical Stimulation and Photosensitive Organic Pigments}

Wiring and hermetic feed-throughs is a major challenge limiting the ability to power many electrodes simultaneously (100). Therefore, techniques suitable for light directed activation of neurons are gaining interest $(121,272)$. Several review papers describe the various optical stimulation methods available and their challenges (273-275). In the scope of this paper, it is interesting to highlight photoelectrical stimulation, in which semiconducting films or particles absorb light to generate charge distribution equivalent to that produced by metallic electrodes (260, 273, 276-279). In particular, photo-capacitive stimulation devices based on semiconducting films share many of the considerations we discussed above.

Photoelectrical stimulation was employed already 40 years ago with silicon to stimulate the retina. Nevertheless, siliconbased devices are rigid and alternatives flexible devices are highly desired (273). A novel photo-stimulation of neural cells was recently proposed, showing that organic pigments can transduce optical signals into electrical stimulation. Such stimulation occurs via a photocapacitive effect (280). Specifically, functional biocompatible semiconductors from hydrogen-bonded organic pigments: metal-free phthalocyanine $(\mathrm{H} 2 \mathrm{Pc})$ and $\mathrm{N}, \mathrm{N}^{\prime}$-dimethyl perylenetracarboxylic diimide (PTCDI) were used (Figure 6B). These materials are stable in air and, in wet environments, they are biocompatible and non-toxic (282). Moreover, they can be tuned to absorb light in the $700-900 \mathrm{~nm}$ region. $\mathrm{H}_{2} \mathrm{Pc}$ absorbs light and functions as a p-type electron donor, while the PTCDI acts as n-type electron acceptor, generating a negatively-charged surface. This photo voltage buildup depolarizes the cell membrane and gives rise to an action potential. A single-, double- and triple-layer $\mathrm{p}-\mathrm{n}$ device can be used for neuronal stimulation, as direct retinal responses 
A
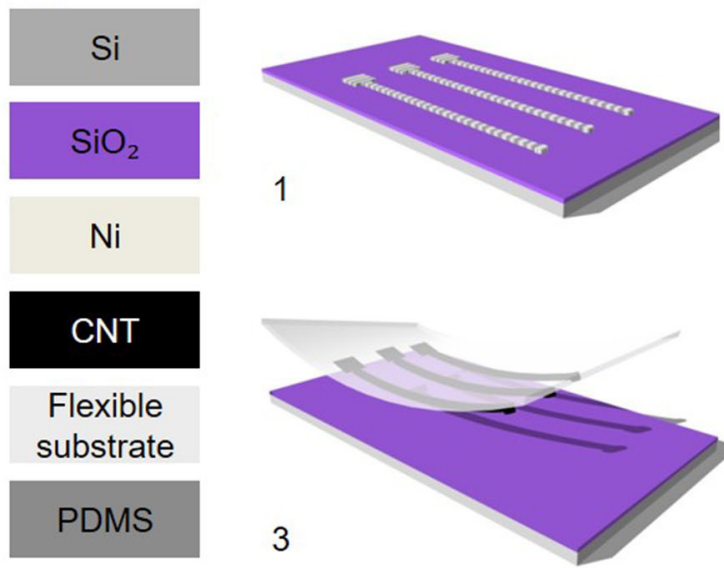

2
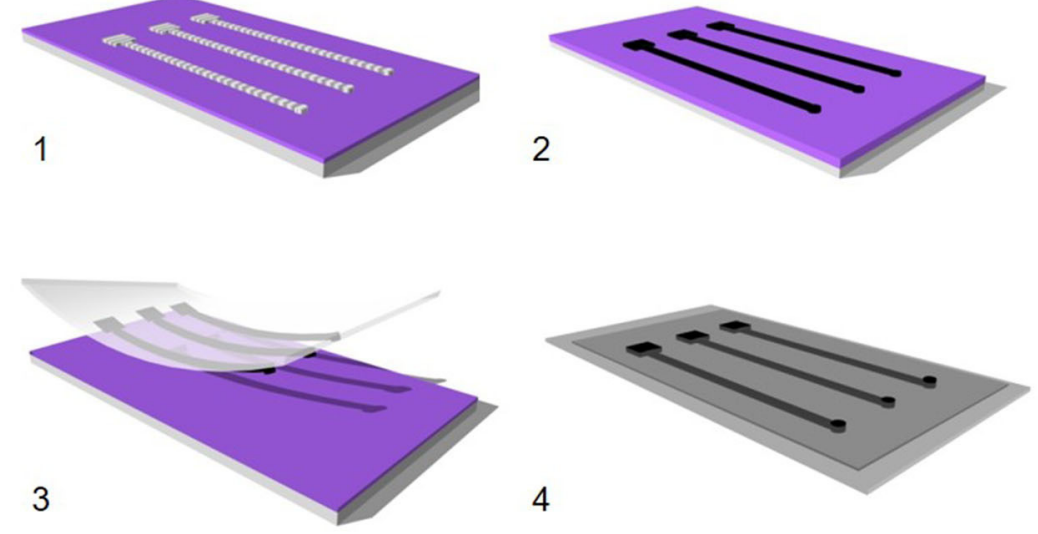

B
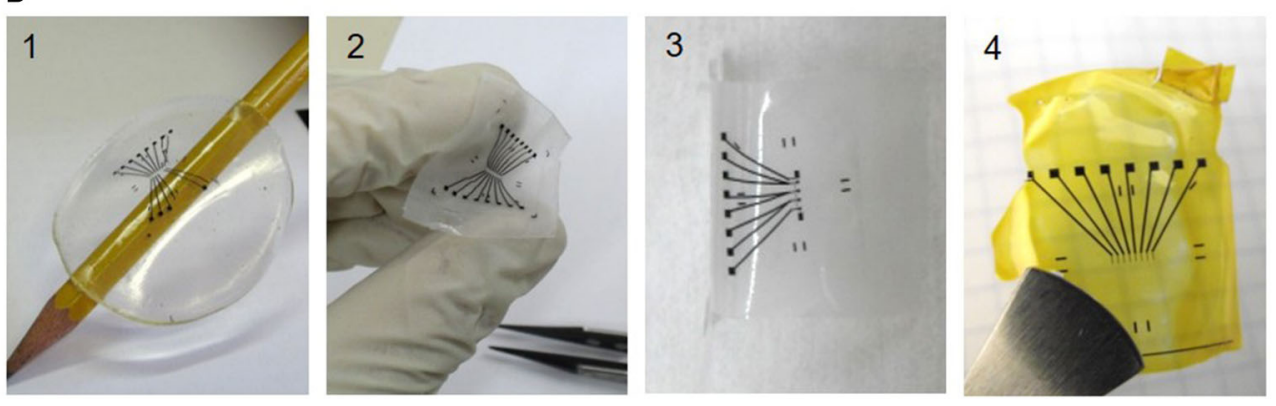

FIGURE 5 | Carbon nanotube-based flexible electrodes for neuronal stimulation. (A) Electrode fabrication scheme. (1) Photolithographically defined Ni catalyst layer. (2) CNT film CVD growth. (3) Film transfer to a polymeric support. (4) A second polymeric layer (PDMS) with predefined holes is bonded with the CNT carrying film for passivation. (B) Different patterns of flexible CNT electrode arrays on different support layers: (1) PDMS, (2) medical adhesive tape, (3) parylene C and (4) polyimide (125). Adapted from David-Pur et al. (125). Copyright 2013, the Author(s).

were observed in embryonic chick retina (Figures 6A,C,D) (280). We studied the transfer of these organic photocapacitor pigments to soft silk films and compared their functionality to films formed on a glass surface. Pigments of varying sizes, ranging from 200 to $1,000 \mu \mathrm{m}$ in diameter, were successfully deposited on silk films (Figure 6E). Voltage transients Vtphotovoltages measured above the pigment regions (Figure 6E) validate electrode functionality (281). Similarly, photoelectrical stimulation of retina via P3HT [poly(3-hexylthiophene-2.5diyl)] with PEDOT:PSS was demonstrated by Maya-Vetencourt et al. (204). Glowacki et al. demonstrated chronic peripheral nerve stimulation via transduction of deep-red light into electrical signals for up to 3 months. Nevertheless, the electrode performance decreases over time in vivo (contradicting accelerated aging results), thus, the device stability and efficiency in vivo should be improved (283). At present, the pigmentbased photocapacitor sizes are still relatively large and improved efficiency is needed to achieve the desired dimensions.

\section{Liquid Metals}

Liquid metals are an emerging material gaining interest in applications for biosensors in wearable and implantable devices (284). Liu et al. extensively researched this field and suggest liquid metals as a preferable alternative that benefit from low mechanical mismatch and low corrosion (285). Liquid metals have a Young's modulus even lower than nerve tissue, setting them as particularly promising materials. Particularly promising are liquid metal gallium $(\mathrm{Ga})$ and gallium-based alloys, which are also considered to be biologically safe. Gallium exhibits a low melting point $\left(29.8^{\circ} \mathrm{C}\right)$ and high thermal $\left(\mathrm{GaIn}_{20}: 26.58\right.$ $\mathrm{Wm}^{-1} \mathrm{~K}^{-1}$ at $\left.20^{\circ} \mathrm{C}\right)$ and electrical conductivity $\left(2.2 \times 10^{6}\right.$ $\mathrm{Sm}^{-1}$ ) (286). Patterning LM can be done by lithography (lift-off), injection, additive approaches (microfluidic inkjet dispensing, stretching, selective wetting, thermal evaporation) and subtractive techniques (in-plane capillarity) (287). Guo et al. presented a flexible microelectrode array for bullfrog sciatic nerve stimulation using LM. The electrode consisted of 4 LM electrodes $500 \mu \mathrm{m}$ in diameter on $500 \mu \mathrm{m}$-thick PDMS film (288). To the best of our knowledge, high-density neural stimulation devices implementing liquid metals have not been presented thus far.

\section{SUMMARY}

Table 2 lists several notable technologies that have been researched and developed for neural stimulation in recent years. Investigation duration, animal model and anchoring procedure vary considerably between studies, with only few 

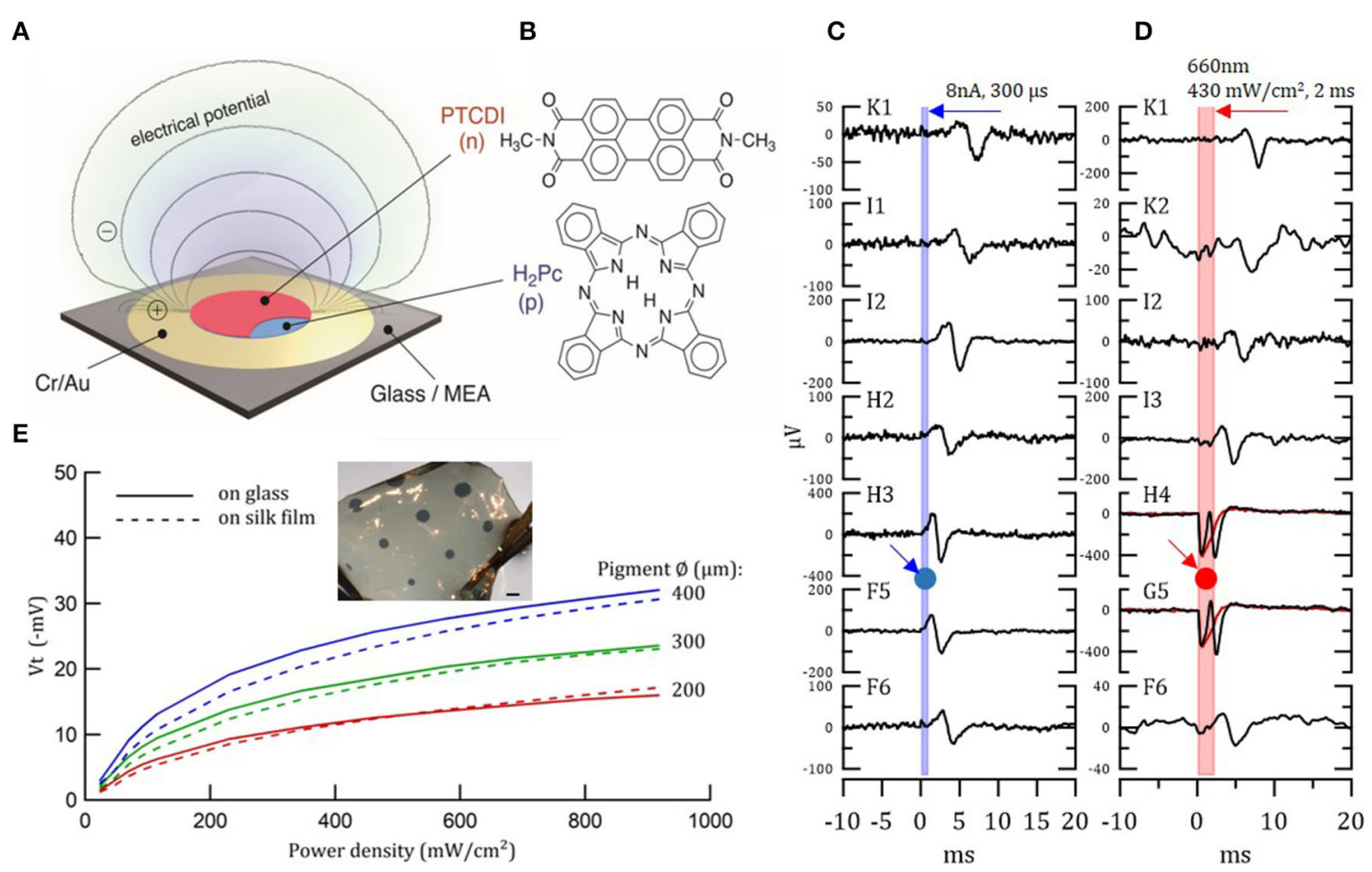

FIGURE 6 | Organic photocapacitor device. (A) Schematic of the photocapacitor device consisting of sequentially evaporated Cr/Au and H2Pc (p-type) and PTCDI (n-type). (B) Molecular structures of the pigment semiconductors. (C,D) Action potential generation in light-insensitive chick embryo retinas in response to current (C) and photoelectrical (D) stimulation, recorded with $30 \mu \mathrm{m}$ diameter TiN electrode MEAs. Retina was placed on the MEA/photocapacitor device with ganglion layer facing down. (C) Direct action potential responses in the retina to $8 \mu \mathrm{A} 300 \mu \mathrm{s}$ biphasic current pulse injected to a single electrode of the MEA (G4). Relative location of the stimulating electrode, G4, is marked by a blue arrow and circle. The graphs illustrate the latency of the response, which increases with increased distance from the stimulating electrode. (D) The same as in (C) direct action potential responses in the retina to $660 \mathrm{~nm} 430 \mathrm{~mW} / \mathrm{cm}^{2} 2 \mathrm{~ms}$ photostimulation through the $\times 40$ microscope objective illuminated from above. Relative location of the illuminated photocapacitor device is marked by a red arrow and circle. Electrodes H4 and G5, which are close to the source, also recorded the electrical signal generated by the device. Reproduced with permission (280). Copyright 2018, Wiley-VCH. (E) Photo-electric responses of illuminated organic photocapacitor pigments on silk film vs. glass deposition. Inset-organic photocapacitor pigments deposited on a silk film. Scale bar-600 $\mu \mathrm{m}(281)$.

studies reporting investigations of different flexible materials under otherwise similar conditions. In Minev et al. (120), $120 \mu \mathrm{m}$ PDMS implants (EDura) were compared to $25 \mu \mathrm{m}$ thick polyimide in a 6-week study. Rats with EDura were indistinguishable from control while PI-implanted rats had significant motor deficits as well as significant deformation of spinal segments under the implant and neuro-inflammatory responses in the vicinity of the implant. A thinner PI implant $(2.5 \mu \mathrm{m})$ was more conformal and exhibited less neuroinflammatory response. A comparison between SMP- and parylene C-based arrays implanted by the spinal cord was reported in Garcia-Sandoval et al. (181). Parylene C introduced slightly more compression, but no significant tissue injury or inflammation for both arrays was observed.

In trying to generalize the results presented in Table 2, we note the following: PDMS, parylene $\mathrm{C}$ and polyimide were extensively studied. PDMS investigations are based on relatively thick films and relatively short durations (several months). Parylene C often suffers from cracks limiting its durability and use to few months. PI is the most established material used also in devices approved for human investigation. A balance between flexibility and longterm stability is a key to establishing a superior substrate material. Emerging materials should be investigated that take into account these considerations and offer the desired improved qualities.

Integration of highly performing electrode materials on flexible surfaces has been demonstrated, yet performances are not yet optimized to the level achieved by rigid devices (see Figure 2). These electrode materials also must demonstrate balance between high performance and device integrity and stability. Finally, device anchoring remains a challenging issue: sutures and tacks are still the common device-anchoring mechanism. These solutions might not be sufficient, and may lead to implant displacement and tissue scarring, which would subsequently lead to a decrease in stimulation efficacy.

It is clear that, while many investigations utilize materials and systems that are presently not suitable for long-term clinical use in humans, these studies provide valuable insights toward better understanding the significance of material flexibility in neural stimulation applications. 
TABLE 2 | Flexible devices for neural stimulation.

\begin{tabular}{|c|c|c|c|c|c|c|}
\hline \multicolumn{2}{|c|}{ Materials } & \multirow[t]{2}{*}{ Device } & \multirow{2}{*}{$\begin{array}{l}\text { Model and } \\
\text { duration }\end{array}$} & \multirow[t]{2}{*}{ Anchoring } & \multirow[t]{2}{*}{ Results of tissue response } & \multirow[t]{2}{*}{ Reference } \\
\hline Substrate & Electrodes & & & & & \\
\hline PDMS $2 \mathrm{~mm}$ thick & $\mathrm{Au}$ & $\begin{array}{l}\text { Cortical } \\
\text { stimulation }\end{array}$ & $\begin{array}{l}\text { In vivo: rats, } 10 \\
\text { weeks }\end{array}$ & $\begin{array}{l}\text { Sutures, screws, } \\
\text { dental acrylic }\end{array}$ & $\begin{array}{l}\text { No mechanical damage; } \\
\text { No notable foreign body response }\end{array}$ & (132) \\
\hline PDMS $1.25 \mathrm{~mm}$ thick & $\mathrm{Pt}$ & $\begin{array}{l}\text { Cuff around sciatic } \\
\text { nerve }\end{array}$ & $\begin{array}{l}\text { In vivo: mice, } \\
\text { acute test }\end{array}$ & $\begin{array}{l}\text { Electrode } \\
\text { wrapped around } \\
\text { the sciatic nerve }\end{array}$ & No thermal damage to the tissue & (129) \\
\hline PDMS $500 \mu \mathrm{m}$ thick & $\mathrm{Pt} / \mathrm{Au}$ & $\begin{array}{l}\text { Epidural spinal } \\
\text { cord stimulation }\end{array}$ & $\begin{array}{l}\text { Minipig, } 6 \text { months; } \\
\text { Performance } \\
\text { evaluation only; }\end{array}$ & - & $\begin{array}{l}\text { Implant position might have shifted, } \\
\text { possible build-up of scar tissue }\end{array}$ & (289) \\
\hline PDMS $140 \mu \mathrm{m}$ thick & $\mathrm{Pt}$ & $\begin{array}{l}\text { Subretinal } \\
\text { stimulation }\end{array}$ & $\begin{array}{l}\text { Electrochemical } \\
\text { characterization; }\end{array}$ & - & NA & $(137)$ \\
\hline PDMS & PEDOT-PEG/CNT & $\begin{array}{l}\text { Tibial nerve } \\
\text { stimulation }\end{array}$ & $\begin{array}{l}\text { In vitro: } \\
\text { cytotoxicity } \\
\text { In vivo: rats, } \\
1 \text { month }\end{array}$ & $\begin{array}{l}\text { Hypodermic } \\
\text { needle shuttle for } \\
\text { insertion }\end{array}$ & $\begin{array}{l}\text { Less scar tissue encapsulation, less } \\
\text { changes to axon size, density and } \\
\text { morphology, reduced macrophage } \\
\text { activation compared to polyimide implants }\end{array}$ & (269) \\
\hline PDMS $64 \mu \mathrm{m}$ thick & $\begin{array}{l}\text { PEDOT:PSS/ } \\
\text { P3HT:PCBM/Ti }\end{array}$ & (nir)Polyretina & $\begin{array}{l}\text { Ex vivo mice; No } \\
\text { tests in vivo }\end{array}$ & Tacks & NA & $(130,290)$ \\
\hline Polyimide $10 \mu \mathrm{m}$ thick & $\mathrm{IrOx}$ & $\begin{array}{l}\text { IRIS retinal implant } \\
\text { (discontinued) }\end{array}$ & $\begin{array}{l}\text { In vivo: Humans } \\
\text { up to } 30 \text { months } \\
\text { follow-up }\end{array}$ & Retinal tacks & $\begin{array}{l}\text { Minor retinal changes, no retinal tissue } \\
\text { damage; } \\
\text { One patient suffered a retinal detachment } \\
\text { during the procedure; no further adverse } \\
\text { reactions observed during the } \\
\text { 3-month follow-up. }\end{array}$ & $(139,291)$ \\
\hline Polyimide $5 \mu \mathrm{m}$ thick & $\mathrm{Au} / \mathrm{lrO}$ & Retinal stimulation & $\begin{array}{l}\text { In vivo: rabbits, } 12 \\
\text { weeks }\end{array}$ & Retinal tack & $\begin{array}{l}\text { Surgery safe but difficult; Retinal } \\
\text { detachment, corneal edema, insufficient } \\
\text { fixation }\end{array}$ & (138) \\
\hline Polyimide $7 \mu \mathrm{m}$ thick & $\begin{array}{l}\mathrm{Pt} \text {, coated with Pt } \\
\text { black/IrO/PEDOT }\end{array}$ & $\begin{array}{l}\text { Sciatic nerve } \\
\text { stimulation }\end{array}$ & $\begin{array}{l}\text { In vitro: } \\
\text { cytotoxicity } \\
\text { In vivo: rat, } \\
\text { 2-4 weeks }\end{array}$ & & $\begin{array}{l}\text { Non-toxic; no significant inflammation; no } \\
\text { rejection response; } \\
\text { Thinner fibrous capsule developed around } \\
\text { the implants compared to PDMS implants }\end{array}$ & (149) \\
\hline Polyimide $12 \mu \mathrm{m}$ thick & $\mathrm{Au} / \mathrm{Pt}$ & $\begin{array}{l}\text { Sciatic nerve } \\
\text { stimulation }\end{array}$ & $\begin{array}{l}\text { In vivo: rats, acute } \\
\text { test }\end{array}$ & & Minimal pressure on the nerve & $(155)$ \\
\hline Polyimide $20 \mu \mathrm{m}$ thick & Ti, Pt, Au & $\begin{array}{l}\text { Deep brain } \\
\text { stimulation }\end{array}$ & $\begin{array}{l}\text { In vivo: rats, } 30 \\
\text { days }\end{array}$ & $\begin{array}{l}\text { Tungsten guide to } \\
\text { insert probe }\end{array}$ & Thin fibrosis around damaged tissue & (296) \\
\hline Polyimide $10 \mu \mathrm{m}$ thick & Pt & $\begin{array}{l}\text { Tripolar spiral cuff } \\
\text { electrode }\end{array}$ & $\begin{array}{l}\text { In vivo: rats, 2-6 } \\
\text { months }\end{array}$ & & $\begin{array}{l}\text { Very mild foreign body reaction; did not } \\
\text { change the nerve shape; no morphological } \\
\text { evidence of axonal loss or demyelination } \\
\text { (except one case of partial demyelination) }\end{array}$ & $(154)$ \\
\hline Polyimide $18 \mu \mathrm{m}$ thick & Pt & Cuff electrode & $\begin{array}{l}\text { In vivo: rabbit, } \\
\text { acute test }\end{array}$ & & NA & (297) \\
\hline
\end{tabular}


TABLE 2 | Continued

\begin{tabular}{|c|c|c|c|c|c|c|}
\hline \multicolumn{2}{|c|}{ Materials } & \multirow[t]{2}{*}{ Device } & \multirow{2}{*}{$\begin{array}{l}\text { Model and } \\
\text { duration }\end{array}$} & \multirow[t]{2}{*}{ Anchoring } & \multirow[t]{2}{*}{ Results of tissue response } & \multirow[t]{2}{*}{ Reference } \\
\hline Substrate & Electrodes & & & & & \\
\hline Polyimide $12 \mu \mathrm{m}$ thick & Pt black & $\begin{array}{l}\text { Cuff vagus nerve } \\
\text { stimulation }\end{array}$ & $\begin{array}{l}\text { In vitro: } \\
\text { cytotoxicity test } \\
\text { in vivo: rats, } \\
\text { acute test }\end{array}$ & Sutures & NA & $(298)$ \\
\hline $\begin{array}{l}\text { Parylene } 16-20 \mu \mathrm{m} \\
\text { thick }\end{array}$ & $\mathrm{Ti} / \mathrm{Pt}$ & $\begin{array}{l}\text { Epiretinal } \\
\text { stimulation; } \\
\text { Spinal } \\
\text { cord stimulation }\end{array}$ & $\begin{array}{l}\text { In vitro: efficacy } \\
\text { and stability test } \\
\text { in vivo: canine } \\
\text { (retinal implant), } \\
6 \text { months; Mice } \\
\text { (spinal } \\
\text { cord implant) } \\
\text { Acute test }\end{array}$ & Sutures, tacks & No obstruction and vessel leakage & $(140)$ \\
\hline Parylene $16 \mu \mathrm{m}$ thick & $\mathrm{Ti} / \mathrm{pt}$ & $\begin{array}{l}\text { Cortical } \\
\text { stimulation }\end{array}$ & $\begin{array}{l}\text { In vivo: rat, } 12 \\
\text { weeks }\end{array}$ & $\begin{array}{l}\text { Ti screws, dental } \\
\text { cement }\end{array}$ & $\begin{array}{l}\text { No adverse events reported; Limited } \\
\text { tissue reaction }\end{array}$ & $(141)$ \\
\hline $\begin{array}{l}\text { Parylene } 6 \mu \mathrm{m} \text { thick } \\
\text { Kapton tape as a } \\
\text { carrier }\end{array}$ & $\mathrm{Ti} / \mathrm{Pt}$ & Cochlear implant & $\begin{array}{l}\text { In vivo: cat, acute } \\
\text { test }\end{array}$ & & NA & $(164)$ \\
\hline Parylene $5 \mu \mathrm{m}$ thick & $\mathrm{H}_{2} \mathrm{Pc} / \mathrm{PTCDI}$ & $\begin{array}{l}\text { Sciatic nerve } \\
\text { stimulation }\end{array}$ & $\begin{array}{l}\text { In vivo: rat, } 3 \\
\text { months }\end{array}$ & $\begin{array}{l}\text { Zip-tie locking } \\
\text { mechanism }\end{array}$ & $\begin{array}{l}\text { No pathological differences between the } \\
\text { implanted and contralateral sciatic nerve; }\end{array}$ & $(283)$ \\
\hline $\begin{array}{l}\text { Silk (grooved) } 90 \mu \mathrm{m} \\
\text { thick }\end{array}$ & $\mathrm{Pt} / \mathrm{Ti} / \mathrm{Au}$ & Neural growth & In vitro only & & NA & $(203)$ \\
\hline Silk $30 \mu \mathrm{m}$ thick & $\begin{array}{l}\text { P3HT and } \\
\text { PEDOT:PSS }\end{array}$ & $\begin{array}{l}\text { Subretinal } \\
\text { stimulation }\end{array}$ & $\begin{array}{l}\text { In vivo: rat, } 6 \\
\text { months }\end{array}$ & & Retina remained intact; no trophic effects & $(204)$ \\
\hline SMP $50 \mu \mathrm{m}$ thick & $\mathrm{TiN} / \mathrm{Au}$ & $\begin{array}{l}\text { Spinal cord } \\
\text { stimulation }\end{array}$ & $\begin{array}{l}\text { In vitro: } \\
\text { accelerated aging } \\
\text { test } \\
\text { In vivo: rats, } \\
16 \text { weeks }\end{array}$ & $\begin{array}{l}\text { Screws and dental } \\
\text { acrylic }\end{array}$ & $\begin{array}{l}\text { Less tissue deformation than } \\
\text { Parylene-C arrays; No significant } \\
\text { astrogliosis or immune reaction; no } \\
\text { noticeable neurological changes }\end{array}$ & $(181)$ \\
\hline SMP $30 \mu \mathrm{m}$ thick & $\mathrm{TiN} / \mathrm{Au}$ & $\begin{array}{l}\text { Sciatic nerve } \\
\text { stimulation }\end{array}$ & $\begin{array}{l}\text { In vitro: } \\
\text { compatibility test } \\
\text { In vivo: rats, } \\
30 \text { days }\end{array}$ & $\begin{array}{l}\text { Sutures, silicone } \\
\text { elastomer }\end{array}$ & $\begin{array}{l}\text { Significantly less inflammation, less fibrotic } \\
\text { vimentin immunoreactivity compared to } \\
\text { silicone cuff }\end{array}$ & $(143)$ \\
\hline SMP $100 \mu \mathrm{m}$ thick & $\mathrm{Au} / \mathrm{Ti} / \mathrm{PI}$ & $\begin{array}{l}\text { Vagus nerve } \\
\text { stimulation }\end{array}$ & $\begin{array}{l}\text { In vivo: rabbit, } \\
\text { acute test }\end{array}$ & & NA & $(184)$ \\
\hline Polyurethane (PU) & PEDOT:PSS & & $\begin{array}{l}\text { In vitro: No tests in } \\
\text { vivo }\end{array}$ & & $\begin{array}{l}\text { Promotes neurite outgrowth, cell } \\
\text { adhesion; }\end{array}$ & $(142)$ \\
\hline
\end{tabular}

\section{DISCUSSION}

While neural stimulation was indeed demonstrated long ago, achieving high resolution, low power along with safe stimulation has proven to be far less obvious $(96,299-301)$. Research in recent decades focused on better understanding how neurostimulation works, to guarantee the safety of the devices (capacitive behavior of the electrodes, stimulation parameters, passivation of the devices), to achieve biocompatibility (nontoxic materials, stability and biocompatibility testing), and to reduce the subsequent physiological reactions (implantation method, material stiffness, anchoring of the device) which often occur when these devices are introduced into the body, and later during continuous mechanical movements. It is important to note that immune response and adverse events vary with the location of implantation, animal model, procedural details and exact material properties (Table 2).
Therefore, short- and long-term studies should be done according to the standard procedures, and in thorough comparative model.

In this review, we discussed how neurostimulation improved over the years. Commercially available cochlear and retinal implants, deep brain stimulation as well as brain-controlled prosthetics are only a few examples. Nevertheless, contemporary implants are typified by relatively high rigidity and weight, rendering them susceptible to increased risk of tissue damage, inflammation and device degradation. The main aim of current research efforts in the field is to develop devices that are substantially more adept to interface with neural tissue, to enable high-resolution, effective stimulation, accompanied by easy implantation and long-term stability. Many recent studies introduced novel materials for implantable electronics applications, including CNTs, polyimide, PDMS, parylene C and organic semiconducting pigments. These materials have the 
potential to overcome the drawbacks of materials used today. Implementation of novel materials in neurostimulating devices will enable further optimization; in particular, better electrodes are needed to achieve high-resolution stimulation and closedloop operation. Finally, the need for instant and stable device anchoring needs more attention.

One of the biggest challenges in attempting to compare different materials for neuro-stimulation is the insufficient use of standardized tests. Standardized lab tests, such as cytotoxicity, are readily available at certified laboratories, yet are often performed in academic research laboratories under different testing conditions. Long-term stability and stimulation efficacy tests are performed under widely varying conditions, making systematic comparison even more challenging. Based on existing reports it is also difficult to directly compare life expectancy values. It appears for example, that the life expectancy of PDMS and Parylene $\mathrm{C}$ are both limited owing to inherent instability but exact values are missing. Moreover, only a few studies performed explicit comparison between materials, or used a

\section{REFERENCES}

1. James CD, Spence AJH, Dowell-Mesfin NM, Hussain RJ, Smith KL, Craighead HG, et al. Extracellular recordings from patterned neuronal networks using planar microelectrode arrays. IEEE Trans Biomed Eng. (2004) 51:1640-8. doi: 10.1109/TBME.2004.827252

2. Weremfo A, Carter P, Hibbert DB, Zhao C. Investigating the interfacial properties of electrochemically roughened platinum electrodes for neural stimulation. Langmuir. (2015) 31:2593-9. doi: 10.1021/la504876n

3. Leber M, Bhandari R, Mize J, Warren DJ, Shandhi MMH, Solzbacher F, et al. Long term performance of porous platinum coated neural electrodes. Biomed Microdevices. (2017) 19:62. doi: 10.1007/s10544-017-0201-4

4. Choi YI, Kim K, Lee S. Fabrication and evaluation of nanostructured microelectrodes for high-spatial resolution in retinal prostheses. Microsyst Technol. (2019) 25:2099-107. doi: 10.1007/s00542-018-4276-5

5. Koklu A, Atmaramani R, Hammack A, Beskok A, Pancrazio JJ, Gnade BE, et al. Gold nanostructure microelectrode arrays for in vitro recording and stimulation from neuronal networks. Nanotechnology. (2019) 30:235501. doi: 10.1088/1361-6528/ab07cd

6. Prochazka A. Neurophysiology and neural engineering: a review. J Neurophysiol. (2017) 118:1292-309. doi: 10.1152/jn.00149.2017

7. Bettinger CJ, Ecker M, Kozai TDY, Malliaras GG, Meng E, Voit W. Recent advances in neural interfaces - Materials chemistry to clinical translation. Mater Res Soc. (2020) 45:655-68. doi: 10.1557/mrs.2020.195

8. Keogh C. Optimizing the neuron-electrode interface for chronic bioelectronic interfacing. Neurosurg Focus. (2020) 49:E7. doi: 10.3171/2020.4.FOCUS20178

9. Chong H, Majerus SJA, Bogie KM, Zorman CA. Non-hermetic packaging of biomedical microsystems from a materials perspective: a review. Med Dev Sensors. (2020) 3:e10082. doi: 10.1002/mds3.10082

10. Horgan J. The forgotten era of brain chips. Sci Am. (2005) 293:6673. doi: 10.1038/scientificamerican1005-66

11. Delgado JM. Physical Control of the Mind: Toward a Psychocivilized Society. Oxford: Harper and Row (1969).

12. Liu W, McGucken E, Clements MA, DeMarco C, Vichienchom $\mathrm{K}$, Hughes $\mathrm{C}$, et al. Multiple-unit artificial retina chipset system to benefit the visually impaired. J Chem Inf Model. (1998) 53:16 89-99.

13. Wise KD, Sodagar AM, Yao Y, Gulari MN, Perlin GE, Najafi K. Microelectrodes, microelectronics, and implantable neural microsystems. Proc IEEE. (2008) 96:1184-1202. doi: 10.1109/JPROC.2008.92 2564 quantitative reference $(120,181)$. We made an effort to highlight these issues.

Finally, it is important to note that future devices should accommodate both neuro-stimulation and recording to enable closed-loop operation, which is highly desired in many applications (302). Although recording and stimulation are closely related technologies, extensive optimization will have to be performed for each application (303-306).

\section{AUTHOR CONTRIBUTIONS}

YH and IV wrote the review together. All authors contributed to the article and approved the submitted version.

\section{FUNDING}

This work was supported by the Israel Science Foundation under the Grant Number 1355/17.

14. Pousaz L. Neuroprosthetics for Paralysis: An New Implant on the Spinal Cord. (2015). Available online at: https://actu.epfl.ch/news/neuroprosthetics-forparalysis-an-new-implant-on-t/ (accessed April 05, 2021).

15. Najafi K, Ji J, Wise KD. Scaling limitations of silicon multichannel recording probes. IEEE Trans Biomed Eng. (1990) 37:1-11. doi: 10.1109/10.43605

16. Najafi K, Hetke JF. Strength characterization of silicon microprobes in neurophysiological tissues. IEEE Trans Biomed Eng. (1990) 37:474481. doi: $10.1109 / 10.55638$

17. Buzsáki G. Large-scale recording of neuronal ensembles. Nat Neurosci. (2004) 7:446-51. doi: 10.1038/nn1233

18. Barthó P, Hirase H, Monconduit L, Zugaro M, Harris KD, Buzsáki G. Characterization of neocortical principal cells and interneurons by network interactions and extracellular features. J Neurophysiol. (2004) 92:6008. doi: 10.1152/jn.01170.2003

19. Berényi A, Somogyvári Z, Nagy AJ, Roux L, Long JD, Fujisawa S, et al. Large-scale, high-density (up to 512 channels) recording of local circuits in behaving animals. J Neurophysiol. (2014) 111:113249. doi: 10.1152/jn.00785.2013

20. Tybrandt K, Khodagholy D, Dielacher B, Stauffer F, Renz AF, Buzsáki G, et al. High-density stretchable electrode grids for chronic neural recording. Adv Mater. (2018) 30:1706520. doi: 10.1002/adma.201706520

21. Ruther P, Paul O. New approaches for CMOS-based devices for large-scale neural recording. Curr Opin Neurobiol. (2015) 32:31-7. doi: 10.1016/j.conb.2014.10.007

22. Campbell PK, Jones KE, Huber RJ, Horch KW, Normann RA. A siliconbased, three-dimensional neural interface: manufacturing processes for an intracortical electrode array. IEEE Trans Biomed Eng. (1991) 38:75868. doi: 10.1109/10.83588

23. Maynard EM, Nordhausen CT, Normann RA. The Utah intracortical electrode array: a recording structure for potential braincomputer interfaces. Electroencephalogr Clin Neurophysiol. (1997) 102:228-39. doi: 10.1016/S0013-4694(96)95176-0

24. Branner A, Stein RB, Normann RA. Selective stimulation of cat sciatic nerve using an array of varying-length microelectrodes. J Neurophysiol. (2001) 85:1585-94. doi: 10.1152/jn.2001.85.4.1585

25. Ledbetter NM, Ethier C, Oby ER, Hiatt SD, Wilder AM, Ko JH, et al. Intrafascicular stimulation of monkey arm nerves evokes coordinated grasp and sensory responses. J Neurophysiol. (2013) 109:580-90. doi: 10.1152/jn.00688.2011

26. Hao Y, Riehle A, Brochier TG. Mapping horizontal spread of activity in monkey motor cortex using single pulse microstimulation. Front Neural Circuits. (2016) 10:104. doi: 10.3389/fncir.2016.00104 
27. Christensen MB, Wark HAC, Hutchinson DT. A histological analysis of human median and ulnar nerves following implantation of Utah slanted electrode arrays. Biomaterials. (2016) 77:23542. doi: 10.1016/j.biomaterials.2015.11.012

28. Brochier T, Zehl L, Hao Y, Duret M, Sprenger J, Denker M, et al. Data descriptor: massively parallel recordings in macaque motor cortex during an instructed delayed reach-to-grasp task. Sci Data. (2018) 5:180055. doi: $10.1038 /$ sdata.2018.55

29. Decramer T, Premereur E, Uytterhoeven M, Van Paesschen W, Van Loon J, Janssen P, et al. Single-cell selectivity and functional architecture of human lateral occipital complex. PLoS Biol. (2019) 17:e3000588. doi: 10.1371/journal.pbio.3000588

30. Schubert MB, Hierzenberger A, Lehner HJ, Werner JH. Optimizing photodiode arrays for the use as retinal implants. Sensors Actuators A Phys. (1999) 74:193-7. doi: 10.1016/S0924-4247(98)00313-6

31. Peachey NS. Subretinal implantation of semiconductor-based photodiodes: Progress and challenges. J Rehabil Res Dev. (1999) 36:371-6.

32. Chow AY, Chow VY, Packo KH, Pollack JS, Peyman GA, Schuchard R. The artificial silicon retina microchip for the treatment of vision loss from retinitis pigmentosa. Arch Ophthalmol. (2004) 122:460-9. doi: 10.1001/archopht.122.4.460

33. Chow AY, Bittner AK, Pardue MT. The artificial silicon retina in retinitis pigmentosa patients (an American ophthalmological association thesis). Trans Am Ophthalmol Soc. (2010) 108:120-54.

34. Zrenner E, Bartz-Schmidt KU, Benav H, Besch D, Bruckmann A, Gabel VP, et al. Subretinal electronic chips allow blind patients to read letters and combine them to words. Proc R Soc B Biol Sci. (2011) 278:148997. doi: $10.1098 / \mathrm{rspb} .2010 .1747$

35. Wang L, Mathieson K, Kamins TI, Loudin JD, Galambos L, Goetz G, et al. Photovoltaic retinal prosthesis: implant fabrication and performance. J Neural Eng. (2012) 9:612-5. doi: 10.1088/1741-2560/9/4/046014

36. Mathieson K, Loudin J, Goetz G, Huie P, Wang L, Kamins TI, et al. Photovoltaic retinal prosthesis with high pixel density. Nat Photonics. (2012) 6:391-7. doi: 10.1038/nphoton.2012.104

37. Adewole DO, Serruya MD, Harris JP, Burrell JC, Petrov D, Chen HI, et al. The evolution of neuroprosthetic interfaces. Crit Rev Biomed Eng. (2016) 44:123-52. doi: 10.1615/CritRevBiomedEng.2016017198

38. Loeb GE. Neural prosthetics: a review of empirical vs. systems engineering strategies. Appl Bionics Biomech. (2018) 2018:1435030. doi: 10.1155/2018/1435030

39. Kook G, Lee SW, Lee HC, Cho IJ, Lee HJ. Neural probes for chronic applications. Micromachines. (2016) 7:179. doi: 10.3390/mi7100179

40. Klein E, Gossler C, Paul O, Ruther P. High-density $\mu$ LED-based optical cochlear implant with improved thermomechanical behavior. Front Neurosci. (2018) 12:659. doi: 10.3389/fnins.2018.00659

41. Yang W, Gong Y, Li W. A review: electrode and packaging materials for neurophysiology recording implants. Front Bioeng Biotechnol. (2021) 8:1515. doi: 10.3389/fbioe.2020.622923

42. Feron K, Lim R, Sherwood C, Keynes A, Brichta A, Dastoor PC. Organic bioelectronics: materials and biocompatibility. Int J Mol Sci. (2018) 19:2382. doi: 10.3390/ijms19082382

43. Taketani M, Baudry M. Advances in Network Electrophysiology Using Multi Electrode Arrays. 1st ed. New York, NY: Springer (2006).

44. Lee W, Someya T. Emerging trends in flexible active multielectrode arrays. Chem Mater. (2019) 31:6347-58. doi: 10.1021/acs.chemmater.9b00165

45. Hodgkin AL, Huxley AF. A quantitative description of membrane current and its application to conduction and excitation in nerve. J Physiol. (1952) 117:500-44. doi: 10.1113/jphysiol.1952.sp004764

46. Cogan SF. Neural stimulation and recording electrodes. Annu Rev Biomed Eng. (2008) 10:275-309. doi: 10.1146/annurev.bioeng.10.061807.160518

47. Günter C, Delbeke J, Ortiz-Catalan M. Safety of long-term electrical peripheral nerve stimulation: review of the state of the art. J Neuroeng Rehabil. (2019) 16:13. doi: 10.1186/s12984-0180474-8

48. Ratner BD, Hoffman AS. Physicochemical surface modification of materials used in medicine. In: Buddy Ratner D, Allan Hoffman S, Frederick Schoen J, Jack Lemons E, editors. Biomaterials Science. Academic Press (2013). p. 259-76. doi: 10.1016/B978-0-08-087780-8.00027-9
49. Vittorio, De M, Martiradonna L, Assad J. Nanotechnology and Neuroscience: Nano-Electronic, Photonic and Mechanical Neuronal Interfacing. New York, NY: Springer US (2014). doi: 10.1007/978-1-4899-8038-0

50. Raz-Prag D, Beit-Yaakov G, Hanein Y. Electrical stimulation of different retinal components and the effect of asymmetric pulses. J Neurosci Methods. (2017) 291:20-7. doi: 10.1016/j.jneumeth.2017.07.028

51. Tan DW, Schiefer MA, Keith MW, Anderson JR, Tyler J, Tyler DJ. A neural interface provides long-term stable natural touch perception. Sci Transl Med. (2014) 6:257ra138. doi: 10.1126/scitranslmed.3008669

52. Patrick EE, Currlin S, Kundu A, Delgado F, Fahmy A, Madler R, et al. Design and assessment of stimulation parameters for a novel peripheral nerve interface. Annu Int Conf IEEE Eng Med Biol Soc. (2018) 2018:54914. doi: 10.1109/EMBC.2018.8513582

53. Lee JI, Im M. Optimal electric stimulus amplitude improves the selectivity between responses of on versus off types of retinal ganglion cells. IEEE Trans Neural Syst Rehabil Eng. (2019) 27:2015-24. doi: 10.1109/TNSRE.2019.2939012

54. Palanker D, Vankov A, Huie P, Baccus S. Design of a highresolution optoelectronic retinal prosthesis. J Neural Eng. (2005) 2:S105-20. doi: 10.1088/1741-2560/2/1/012

55. Sekirnjak C, Hottowy P, Sher A, Dabrowski W, Litke AM, Chichilnisky EJ. High-resolution electrical stimulation of primate retina for epiretinal implant design. J Neurosci. (2008) 28:4446-56. doi: 10.1523/JNEUROSCI.5138-07.2008

56. Wallach G, Lallouette J, Herzog N, De Pittà M, Jacob, Ben E, et al. Glutamate mediated astrocytic filtering of neuronal activity. PLoS Comput Biol. (2014) 10:e1003964. doi: 10.1371/journal.pcbi.1003964

57. Walston ST, Chow RH, Weiland JD. Direct measurement of bipolar cell responses to electrical stimulation in wholemount mouse retina. J Neural Eng. (2018) 15:046003. doi: 10.1088/1741-2552/aab4ed

58. Ghazavi A, Maeng J, Black M, Salvi S, Cogan SF. Electrochemical characteristics of ultramicro-dimensioned SIROF electrodes for neural stimulation and recording. J Neural Eng. (2020) 17:016022. doi: 10.1088/1741-2552/ab52ab

59. Merrill DR, Bikson M, Jefferys JGR. Electrical stimulation of excitable tissue: design of efficacious and safe protocols. J Neurosci Methods. (2005) 141:17198. doi: 10.1016/j.jneumeth.2004.10.020

60. Rutten WLC. Selective electrical interfaces with the nervous system. Annu Rev Biomed Eng. (2002) 4:40752. doi: 10.1146/annurev.bioeng.4.020702.153427

61. Vomero M, Castagnola E, Ciarpella F, Maggiolini E, Goshi N, Zucchini E, et al. Highly stable glassy carbon interfaces for long-term neural stimulation and low-noise recording of brain activity. Sci Rep. (2017) 7:40332. doi: 10.1038/srep40332

62. Nimbalkar S, Castagnola E, Balasubramani A, Scarpellini A, Samejima S, Khorasani A, et al. Ultra-capacitive carbon neural probe allows simultaneous long-term electrical stimulations and high-resolution neurotransmitter detection. Sci Rep. (2018) 8:6958. doi: 10.1038/s41598-018-25198-x

63. Vomero M, Oliveira A, Ashouri D, Eickenscheidt M, Stieglitz T. Graphitic carbon electrodes on flexible substrate for neural applications entirely fabricated using infrared nanosecond laser technology. Sci Rep. (2018) 8:14749. doi: 10.1038/s41598-018-33083-w

64. Gueli C, Vomero M, Sharma S, Stieglitz T. Integration of micro-patterned carbon fiber mats into polyimide for the development of flexible implantable neural devices. Proc Annu Int Conf IEEE Eng Med Biol Soc EMBS. (2019) 2019:3931-4. doi: 10.1109/EMBC.2019.8856960

65. Huynh NU, Kassegne S, Youssef G. Comparative study of tuning of microfabrication parameters for improving electrochemical performance of platinum and glassy carbon microelectrodes in neural prosthetics. Microsyst Technol. (2019) 26:775-85. doi: 10.1007/s00542-019-04618-6

66. Zhang X, Chen C, Ni G, Hai Y, Chen B, Zhou Y, et al. Carbon multielectrode arrays as peripheral nerve interface for neural recording and nerve stimulation. Med Dev Sensors. (2019) 2:e10026. doi: 10.1002/mds3.10026

67. Lee JH, Kim H, Kim JH, Lee SH. Soft implantable microelectrodes for future medicine: prosthetics, neural signal recording and neuromodulation. Lab Chip. (2016) 16:959-76. doi: 10.1039/C5LC00842E

68. Robblee LS, McHardy J, Agnew WF, Bullara LA. Electrical stimulation with Pt electrodes. VII. Dissolution of $\mathrm{Pt}$ electrodes during electrical 
stimulation of the cat cerebral cortex. J Neurosci Methods. (1983) 9:3018. doi: 10.1016/0165-0270(83)90062-6

69. Agnew WF, Yuen TGH, McCreery DB, Bullara LA. Histopathologic evaluation of prolonged intracortical electrical stimulation. Exp Neurol. (1986) 92:162-85. doi: 10.1016/0014-4886(86)90132-9

70. Cogan SF, Guzelian AA, Agnew WF, Yuen TGH, McCreery DB. Over-pulsing degrades activated iridium oxide films used for intracortical neural stimulation. J Neurosci Methods. (2004) 137:141-50. doi: 10.1016/j.jneumeth.2004.02.019

71. Pfau J, Stieglitz T, Ordonez JS. Mechanical deformation and chemical degradation of thin-film platinum under aging and electrical stimulation. Int IEEE/EMBS Conf Neural Eng. (2017) 2017:166-9. doi: 10.1109/NER.2017.8008318

72. Huang TW, Kamins TI, Chen ZC, Wang, B.-Y., Bhuckory M, et al. Verticaljunction photodiodes for smaller pixels in retinal prostheses. J Neural Eng. (2021) 18:036015. doi: 10.1088/1741-2552/abe6b8

73. Palanker D, Vankov A, Huie P, Baccus S. Design of a highresolution optoelectronic retinal prosthesis. J Neural Eng. (2005) 2:S105-20. doi: 10.1117/12.590964

74. US-FDA. Use of International Standard ISO 10993-1, "Biological evaluation of medical devices-Part 1: evaluation and testing within a risk management process" guidance for industry and Food and Drug Administration staff. U.S. Dep Heal Hum Serv Food Drug Adm. (2020) 2020:1-68. Available online at: https://www.fda.gov/regulatory-information/search-fda-guidancedocuments/use-international-standard-iso-10993-1-biological-evaluationmedical-devices-part-1-evaluation-and (accessed April 05, 2021).

75. Ratner B, Hoffman A, Schoen F, Lemons J. Biomaterials Science - An Introduction to Materials in Medicine. Academic Press (2012). p. 1573.

76. Hassler C, Von Metzen RP, Ruther P, Stieglitz T. Characterization of parylene $\mathrm{C}$ as an encapsulation material for implanted neural prostheses. J Biomed Mater Res. (2010) 93:266-74. doi: 10.1002/jbm.b.31584

77. Shepherd RK, Villalobos J, Burns O, Nayagam DAX. The development of neural stimulators: a review of preclinical safety and efficacy studies. J Neural Eng. (2018) 15:041004. doi: 10.1088/1741-2552/aac43c

78. Edell DJ, Toi, Van V, McNeil VM, Clark LD. Factors influencing the biocompatibility of insertable silicon microshafts in cerebral cortex. IEEE Trans Biomed Eng. (1992) 39:635-43. doi: 10.1109/10.141202

79. Szarowski DH, Andersen MD, Retterer S, Spence AJ, Isaacson M, Craighead HG, et al. Brain responses to micro-machined silicon devices. Brain Res. (2003) 983:23-35. doi: 10.1016/S0006-8993(03)03023-3

80. Subbaroyan J, Martin DC, Kipke DR. A finite-element model of the mechanical effects of implantable microelectrodes in the cerebral cortex. $J$ Neural Eng. (2005) 2:103-13. doi: 10.1088/1741-2560/2/4/006

81. Jensen W, Yoshida K, Hofmann UG. In-vivo implant mechanics of flexible, silicon-based ACREO microelectrode arrays in rat cerebral cortex. IEEE Trans Biomed Eng. (2006) 53:934-40. doi: 10.1109/TBME.2006.8 72824

82. Barrese JC, Aceros J, Donoghue JP. Scanning electron microscopy of chronically implanted intracortical microelectrode arrays in non-human primates James. J Neural Eng. (2016) 13:026003. doi: $10.1088 / 1741-2560 / 13 / 2 / 026003$

83. Delbeke J, Haesler S, Prodanov D. Failure modes of implanted neural interfaces. In: Guo L, editor. Neural Interface Engineering. Cham: Springer Nature Switzerland AG (2020). p. 123172. doi: 10.1007/978-3-030-41854-0_6

84. Prodanov D, Delbeke J. Mechanical and biological interactions of implants with the brain and their impact on implant design. Front Neurosci. (2016) 10:11. doi: 10.3389/fnins.2016.00011

85. Stiller AM, Basavarajappa L, Brown K, Voit W, Pancrazio JJ, Hoyt K. Elastrographic assessment of micromotion-induced strain in tissue adjacent to intracortical implants in rat. IEEE Int. Ultrason. Symp. (2019) 2019:43538. doi: 10.1109/ULTSYM.2019.8925593

86. Gulino M, Kim D, Pané S, Santos SD, Pêgo AP. Tissue response to neural implants: the use of model systems toward new design solutions of implantable microelectrodes. Front Neurosci. (2019) 13:689. doi: 10.3389/fnins.2019. 00689
87. Lei X, Kane S, Cogan S, Lorach H, Galambos L, Huie P, et al. SiC protective coating for photovoltaic retinal prostheses. J Neural Eng. (2017) 13:046016. doi: 10.1088/1741-2560/13/4/046016

88. Szostak KM, Grand L, Constandinou TG. Neural interfaces for intracortical recording: Requirements, fabrication methods, and characteristics. Front Neurosci. (2017) 11:665. doi: 10.3389/fnins.2017.0 0665

89. Kovacs GTA. Introduction to the theory, design and modeling of thin-film microelectrodes for neural interfaces. In: Stenger DA, McKenna T, editors. Enabling Technologies for Cultured Neural Networks. Academic Press (1994). p. 121-66.

90. Fromherz P, Stett A. Silicon-neuron junction: capacitive stimulation of an individual neuron on a silicon chip. Phys Rev Lett. (1995) 75:16704. doi: 10.1103/PhysRevLett.75.1670

91. Eickenscheidt M, Jenkner M, Thewes R, Fromherz P, Zeck G. Electrical stimulation of retinal neurons in epiretinal and subretinal configuration using a multicapacitor array. J Neurophysiol. (2012) 107:2742-55. doi: 10.1152/jn.00909.2011

92. Janders M, Egert U, Stelzle M, Nisch W. Novel thin film titanium nitride micro-electrodes with excellent charge transfer capability for cell stimulation and sensing applications. Proc 18th Annu Int Conf IEEE Eng Med Biol Soc. (1997) 2011:245-47. doi: 10.1109/IEMBS.1996.656936

93. Guenther E, Tröger B, Schlosshauer B, Zrenner E. Long-term survival of retinal cell cultures on retinal implant materials. Vis Res. (1999) 39:398894. doi: 10.1016/S0042-6989(99)00128-5

94. Harnack D, Winter C, Meissner W, Reum T, Kupsch A, Morgenstern R. The effects of electrode material, charge density and stimulation duration on the safety of high-frequency stimulation of the subthalamic nucleus in rats. $J$ Neurosci Methods. (2004) 138:207-16. doi: 10.1016/j.jneumeth.2004.04.019

95. Bareket-Keren L, Hanein Y. Carbon nanotube-based multi electrode arrays for neuronal interfacing: progress and prospects. Front. Neural Circuits. (2013) 6:122. doi: 10.3389/fncir.2012.00122

96. Klooster DCW, de Louw AJA, Aldenkamp AP, Besseling RMH, Mestrom RMC, Carrette S, et al. Technical aspects of neurostimulation: Focus on equipment, electric field modeling, stimulation protocols. Neurosci Biobehav Rev. (2016) 65:113-41. doi: 10.1016/j.neubiorev.2016.02.016

97. Musk E. An integrated brain-machine interface platform with thousands of channels. J Med Internet Res. (2019) 21:e16194. doi: 10.2196/16194

98. Yin M, Borton DA, Aceros J, Patterson WR, Nurmikko A. A 100channel hermetically sealed implantable device for chronic wireless neurosensing applications. IEEE Trans Biomed Circuits Syst. (2013) 7:11528. doi: 10.1109/TBCAS.2013.2255874

99. Zhou DD, Dorn JD, Greenberg R. The Argus (R II retinal prosthesis system : an overview. IEEE Int Conf Mulitmedia Expo Work. (2013) 2013:16. doi: 10.1109/ICMEW.2013.6618428

100. Ganesan K, Garrett DJ, Ahnood A, Shivdasani MN, Tong $\mathrm{W}$, Turnley AM, et al. An all-diamond, hermetic electrical feedthrough array for a retinal prosthesis. Biomaterials. (2014) 35:908-15. doi: 10.1016/j.biomaterials.2013.10.040

101. Jiang G, Zhou DD. technology advances challenges in hermetic packaging for implantable medical devices. In: Zhou D, Greenbaum E, editors. Biological and Medical Physics, Biomedical Engineering. New York, NY: Springer (2009). doi: 10.1007/978-0-387-98120-8_2

102. Shen K, Maharbiz MM. Ceramic packaging in neural implants. J Neural Eng. (2021) 18:025002. doi: 10.1088/1741-2552/abd683

103. Vanhoestenberghe A, Donaldson N. Corrosion of silicon integrated circuits and lifetime predictions in implantable electronic devices. J Neural Eng. (2013) 10:031002. doi: 10.1088/1741-2560/10/3/031002

104. Song E, Li J, Rogers JA. Barrier materials for flexible bioelectronic implants with chronic stability - Current approaches and future directions. APL Mater. (2019) 7:050902. doi: 10.1063/1.5094415

105. ASTM F1980-07. Standard Guide For Accelerated Aging of Sterile Barrier Systems For Medical Devices (2018). Available online at: https://www.astm. org/DATABASE.CART/HISTORICAL/F1980-07.htm (Accessed April 05, 2021).

106. Hosseini SM, Rihani R, Batchelor B, Stiller AM, Pancrazio JJ, Voit WE, et al. Softening shape memory polymer substrates for bioelectronic 
devices with improved hydrolytic stability. Front Mater. (2018) 5:66. doi: 10.3389/fmats.2018.00066

107. Roessler G, Laube T, Brockmann C, Kirschkamp T, Mazinani B, MenzelSevering J, et al. Angiographic findings following tack fixation of a wireless epiretinal retina implant device in blind RP patients. Graefe's Arch Clin Exp Ophthalmol. (2011) 249:1281-6. doi: 10.1007/s00417-011-1653-5

108. Gu C, Ni T, Verter EE, Redmond RW, Kochevar IE, Yao M. Photochemical tissue bonding: a potential strategy for treating limbal stem cell deficiency. Lasers Surg Med. (2011) 43:433-42. doi: 10.1002/lsm.21066

109. Ark M, Cosman PH, Boughton P, Dunstan CR. Review: Photochemical Tissue Bonding (PTB) methods for sutureless tissue adhesion. Int J Adhes Adhes. (2016) 71:87-98. doi: 10.1016/j.ijadhadh.2016.08.006

110. Menzel-Severing J, Laube T, Brockmann C, Bornfeld N, Mokwa W, Mazinani $\mathrm{B}$, et al. Implantation and explantation of an active epiretinal visual prosthesis: 2-year follow-up data from the EPIRET3 prospective clinical trial. Eye. (2012) 26:502-9. doi: 10.1038/eye.2012.35

111. Humayun MS, Dorn JD, Da Cruz L, Dagnellie G, Sahel JA. Interim results from the international trial of second sight's visual prosthesis. Ophthalmology. (2012) 119:779-88. doi: 10.1016/j.ophtha.2011. 09.028

112. Cheng DL, Greenberg PB, Borton DA. Advances in retinal prosthetic research: a systematic review of engineering and clinical characteristics of current prosthetic initiatives. Curr Eye Res. (2017) 42:334-47. doi: 10.1080/02713683.2016.1270326

113. Fleming JE, Dunn E, Lowery MM. Simulation of closed-loop deep brain stimulation control schemes for suppression of pathological beta oscillations in Parkinson's disease. Front Neurosci. (2020) 14:166. doi: $10.3389 /$ fnins.2020.00166

114. Parastarfeizabadi M, Kouzani AZ. Advances in closed-loop deep brain stimulation devices. J Neuroeng Rehabil. (2017) 14:79. doi: 10.1186/s12984-017-0295-1

115. Ferleger BI, Houston B, Thompson MC, Cooper SS, Sonnet KS, Ko AL, et al. Fully implanted adaptive deep brain stimulation in freely moving essential tremor patients. J Neural Eng. (2020) 17:056026. doi: 10.1088/1741-2552/abb416

116. Lacour SP, Benmerah S, Tarte E, Fitzgerald J, Serra J, McMahon $\mathrm{S}$, et al. Flexible and stretchable micro-electrodes for in vitro and in vivo neural interfaces. Med Biol Eng Comput. (2010) 48:94554. doi: 10.1007/s11517-010-0644-8

117. Rogers JA, Someya T, Huang Y. Materials and mechanics for stretchable electronics. Science. (2010) 327:1603-7. doi: 10.1126/science.1182383

118. Hassler C, Boretius T, Stieglitz T. Polymers for neural implants. J Polym Sci Part B Polym Phys. (2011) 49:18-33. doi: 10.1002/polb.22169

119. Kim DH, Ghaffari R, Lu N, Rogers JA. Flexible and stretchable electronics for biointegrated devices. Annu Rev Biomed Eng. (2012) 14:11328. doi: 10.1146/annurev-bioeng-071811-150018

120. Minev IR, Musienko P, Hirsch A, Barraud Q, Wenger N, Asboth L, et al. Electronic dura mater for long-term multimodal neural interfaces. Biomaterials. (2015) 347:159-64. doi: 10.1126/science.1260318

121. Malliaras GG, Deisseroth K, Wang H, Rivnay J, Fenno L. Next-generation probes, particles, and proteins for neural interfacing. Sci Adv. (2017) 3:e1601649. doi: 10.1126/sciadv.1601649

122. Wang $\mathrm{Y}$, Zhu $\mathrm{H}$, Yang $\mathrm{H}$, Argall $\mathrm{AD}$, Luan $\mathrm{L}$, Xie $\mathrm{C}$, et al. Nano functional neural interfaces. Nano Res. (2018) 11:5065106. doi: $10.1007 / \mathrm{s} 12274-018-2127-4$

123. Obidin N, Tasnim F, Dagdeviren C. The future of neuroimplantable devices: a materials science and regulatory perspective. Adv Mater. (2020) 32:1901482. doi: 10.1002/adma.201901482

124. Seymour JP, Wu F, Wise KD, Yoon E. State-of-the-art memes and microsystem tools for brain research. Microsyst Nanoeng. (2017) 3:16066. doi: $10.1038 /$ micronano.2016.66

125. David-Pur M, Bareket-Keren L, Beit-Yaakov G, Raz-Prag D, Hanein Y. Allcarbon-nanotube flexible multi-electrode array for neuronal recording and stimulation. Biomed Microdev. (2014) 16:43-53. doi: 10.1007/s10544-0139804-6

126. Keefer EW, Botterman BR, Romero MI, Rossi AF, Gross GW. Carbon nanotube coating improves neuronal recordings. Nat Nanotechnol. (2008) 3:434-9. doi: 10.1038/nnano.2008.174
127. Luo X, Weaver CL, Zhou DD, Greenberg R, Cui XT. Highly stable carbon nanotube doped poly(3,4-ethylenedioxythiophene) for chronic neural stimulation. Biomaterials. (2011) 32:55517. doi: 10.1016/j.biomaterials.2011.04.051

128. Wolf MP, Salieb-Beugelaar GB, Hunziker P. PDMS with designer functionalities-Properties, modifications strategies, and applications. Prog Polym Sci. (2018) 83:97-134. doi: 10.1016/j.progpolymsci.2018.06.001

129. Song K, Park SE, Lee S, Kim H, Lee SH, Youn I. Compact optical nerve cuff electrode for simultaneous neural activity monitoring and optogenetic stimulation of peripheral nerves. Sci Rep. (2018) 8:15630. doi: $10.1038 / \mathrm{s} 41598-018-33695-2$

130. Ferlauto L, Airaghi Leccardi MJI, Chenais NAL, Gilliéron SCA, Vagni $\mathrm{P}$, Bevilacqua $\mathrm{M}$, et al. Design and validation of a foldable and photovoltaic wide-field epiretinal prosthesis. Nat Commun. (2018) 9:992. doi: 10.1038/s41467-018-03386-7

131. Ochoa M, Wei P, Wolley AJ, Otto KJ, Ziaie B. A hybrid PDMSParylene subdural multi-electrode array. Biomed Microdev. (2013) 15:43743. doi: 10.1007/s10544-013-9743-2

132. Russell C, Kissane RWP, Steenson DP, Chakrabarty S. A novel simplistic fabrication technique for cranial epidural electrodes for chronic recording and stimulation in rats. J Neurosci Methods. (2019) 311:239-42. doi: 10.1016/j.jneumeth.2018.10.036

133. Graudejus O, Görrn P, Wagner S. Controlling the morphology of gold films on poly(dimethylsiloxane). ACS Appl Mater Interfaces. (2010) 2:192733. doi: $10.1021 / \mathrm{am} 1002537$

134. Simon D, Ware T, Marcotte R, Lund BR, Smith DW, Di Prima $\mathrm{M}$, et al. A comparison of polymer substrates for photolithographic processing of flexible bioelectronics. Biomed Microdev. (2013) 15:92539. doi: $10.1007 / \mathrm{s} 10544-013-9782-8$

135. Jeong J, Chou N, Kim S. Long-term characterization of neural electrodes based on parylene-caulked polydimethylsiloxane substrate. Biomed Microdevices. (2016) 18:42. doi: 10.1007/s10544-016-0065-Z

136. Lei Y, Liu Y, Wang W, Wu W, Li Z. Studies on Parylene C-caulked PDMS (pcPDMS) for low permeability required microfluidics applications. Lab Chip. (2011) 11:1385-8. doi: 10.1039/c0lc00486c

137. Seo HW, Kim N, Kim S. Fabrication of subretinal 3D microelectrodes with hexagonal arrangement. Micromachines. (2020) 11:19-24. doi: 10.3390/mil1050467

138. Lohmann TK, Haiss F, Schaffrath K, Schnitzler AC, Waschkowski F, Barz C, et al. The very large electrode array for retinal stimulation (VLARS)-A concept study. J Neural Eng. (2019) 16:066031. doi: 10.1088/1741-2552/ab4113

139. Keserue M, Post N, Hornig R, Zeitz, ORichard G. Long term tolerability of the first wireless implant for electrical epiretinal stimulation. Invest Ophthalmol Vis Sci. (2009) 50:4226. doi: 10.1167/iovs.09-3767

140. Rodger DC, Fong AJ, Li W, Ameri H, Ahuja AK, Gutierrez C, et al. Flexible parylene-based multielectrode array technology for high-density neural stimulation and recording. Sensors Actuators B Chem. (2008) 132:44960. doi: 10.1016/j.snb.2007.10.069

141. Torres-Martinez N, Ratel D, Crétallaz C, Gaude C, Maubert S, Divoux JL, et al. Reliability of parylene-based multielectrode arrays chronically implanted in adult rat brains, and evidence of electrical stimulation on contact impedance. J Neural Eng. (2019) 16:066047. doi: 10.1088/1741-2552/a b3836

142. Cuttaz E, Goding J, Vallejo-Giraldo C, Aregueta-Robles U, Lovell N, Ghezzi D, et al. Conductive elastomer composites for fully polymeric, flexible bioelectronics. Biomater Sci. (2019) 7:1372-85. doi: 10.1039/C8BM0 $1235 \mathrm{~K}$

143. González-González MA, Kanneganti A, Joshi-Imre A, HernandezReynoso AG, Bendale G, Modi R, et al. Thin film multi-electrode softening cuffs for selective neuromodulation. Sci Rep. (2018) 8:16390. doi: 10.1038/s41598-018-34566-6

144. Georgiev A, Dimov D, Spassova E, Assa J, Dineff P, Danev G. Chemical and physical properties of polyimides: biomedical and engineering applications. In: Abadie MJM, editor. High performance polymers - polyimides based - from chemistry to applications. IntechOpen. (2012). p. 65-84. Available online at: https://www.intechopen.com/books/high-performance-polymers- 
polyimides-based-from-chemistry-to-applications/chemical-and-physicalproperties-of-polyimides-biomedical-and-engineering-applications (accessed April 5, 2021).

145. Sun Y, Lacour SP, Brooks RA, Rushton N, Fawcett J, Cameron RE. Assessment of the biocompatibility of photosensitive polyimide for implantable medical device use. J Biomed Mater Res A. (2009) 90:64855. doi: 10.1002/jbm.a.32125

146. Rehberger F, Stieglitz T, Eickenscheidt M. Micro-folded 3D neural electrodes fully integrated in polyimide. Proc Annu Int Conf IEEE Eng Med Biol Soc. (2018) 2018:4587-90. doi: 10.1109/EMBC.2018.8513144

147. Chen Y, Kim YS, Tillman BW, Yeo WH, Chun Y. Advances in materials for recent low-profile implantable bioelectronics. Materials. (2018) 11:522. doi: 10.3390/ma11040522

148. Ordonez J, Schuettler M, Boehler C, Boretius T, Stieglitz T. Thin films and microelectrode arrays for neuroprosthetics. MRS Bull. (2012) 37:5908. doi: $10.1557 / \mathrm{mrs} .2012 .117$

149. Stieglitz $T$, Schuettler M, Rubehn B, Boretius $T$, Badia J, Navarro $\mathrm{X}$. Evaluation of polyimide as substrate material for electrodes to interface the peripheral nervous system. In: 2011 5th International IEEE/EMBS Conference on Neural Engineering. Cancun: IEEE (2011). doi: 10.1109/NER.2011.5910602

150. Constantin CP, Aflori M, Damian RF, Rusu RD. Biocompatibility of polyimides: a mini-review. Materials. (2019) 12:3166. doi: 10.3390/ma12193166

151. Rathbun DL, Shivdasani MN, Guo T, Fried S, Lovell NH, Hessburg P. The eye and the chip 2019-conference report. J Neural Eng. (2020) 17:010401. doi: 10.1088/1741-2552/ab60c0

152. Ayton LN, Barnes N, Dagnelie G, Fujikado T, Goetz G, Hornig R, et al. An update on retinal prostheses. Clin Neurophysiol. (2020) 131:138398. doi: 10.1016/j.clinph.2019.11.029

153. MacEwan MR, Zellmer ER, Wheeler JJ, Burton H, Moran DW. Regenerated sciatic nerve axons stimulated through a chronically implanted macro-sieve electrode. Front Neurosci. (2016) 10:557. doi: 10.3389/fnins.2016.00557

154. Rodriguez JF, Ceballos D, Schuttler M, Valero A, Valderrama E, Stieglitz $\mathrm{T}$, et al. Polyimide cuff electrodes for peripeheral nerve stimulation. J Neurosci Methods. (2000) 98:105-18. doi: 10.1016/S0165-0270(00) 00192-8

155. Lee S, Sheshadri S, Xiang Z, Delgado-Martinez I, Xue N, Sun T, et al. Selective stimulation and neural recording on peripheral nerves using flexible split ring electrodes. Sensors Actuators B Chem. (2017) 242:116570. doi: $10.1016 /$ j.snb.2016.09.127

156. Xiang Z, Yen SC, Xue N, Sun T, Tsang WM, Zhang S, et al. Ultrathin flexible polyimide neural probe embedded in a dissolvable maltose-coated microneedle. J Micromech Microeng. (2014) 24:065015. doi: 10.1088/0960-1317/24/6/065015

157. Kim TL, McCall JG, Jung YH, Huang X, Siuda ER. Injectable, cellulas-scale optoelectronics with applications for wireless optogenetics. Science. (2013) 340:211-7. doi: 10.1126/science.1232437

158. Hassler C, Ehler N, Singh V, Xie Y, Martini N, Kirch RD, et al. Fabrication Q15 and implantation of hydrogel coated, flexible polyimide electrodes. In: International IEEE/EMBS Conference on Neural Engineering. Montpellier (2015). doi: 10.1109/NER.2015.7146684

159. Tan KL, Cheng MY, Chen WG, Lim RQ, Ramona M, Damalerio B, et al. Polyethylene glycol-coated polyimide-based probe with neural recording IC for chronic neural recording. Adv Mater Res. (2013) 849:1838. doi: 10.4028/www.scientific.net/AMR.849.183

160. Ortigoza-Diaz J, Scholten K, Larson C, Cobo A, Hudson T, Yoo $\mathrm{J}$, et al. Techniques and considerations in the microfabrication of parylene C microelectromechanical systems. Micromachines. (2018) 9:422. doi: 10.3390/mi9090422

161. Rodger DC, Li W, Fong AJ, Ameri H, Meng E, Burdick JW, et al. Flexible microfabricated parylene multielectrode arrays for retinal stimulation and spinal cord field modulation. In: Proc. 4th International IEEE-EMBS Special Topic Conference on Microtechnologies in Medicine and Biology. Okinawa (2006). p. 31-4.

162. Li W, Rodger DC, Tai YC. Integrated wireless neurostimulator. In: Proc. IEEE Int. Conf. Micro Electro Mech. Syst. Sorrento (2009). doi: 10.1109/MEMSYS.2009.4805365
163. Li W, Rodger DC, Pinto A, Meng E, Weiland JD, Humayun MS, et al. Parylene-based integrated wireless single-channel neurostimulator. Sensors Actuators A Phys. (2011) 166:193-200. doi: 10.1016/j.sna.2010.03.003

164. Xu Y, Luo C, Zeng FG, Middlebrooks JC, Lin HW, You Z. Study of the carrier-aided thin film electrode array design for cochlear insertion. Micromachines. (2018) 9:206. doi: 10.3390/mi9050206

165. Minnikanti S, Diao G, Pancrazio JJ, Xie X, Rieth L, Solzbacher F, et al. Lifetime assessment of atomic-layer-deposited Al2O 3-Parylene $\mathrm{C}$ bilayer coating for neural interfaces using accelerated age testing and electrochemical characterization. Acta Biomater. (2014) 10:9607. doi: 10.1016/j.actbio.2013.10.031

166. Xie X, Rieth L, Williams L, Negi S, Bhandari R, Caldwell R, et al. Longterm reliability of $\mathrm{Al} 2 \mathrm{O} 3$ and Parylene $\mathrm{C}$ bilayer encapsulated Utah electrode array based neural interfaces for chronic implantation. J Neural Eng. (2015) 11:026016. doi: 10.1088/1741-2560/11/2/026016

167. De La Oliva N, Mueller M, Stieglitz T, Navarro X, Del Valle. J. On the use of Parylene C polymer as substrate for peripheral nerve electrodes. Sci Rep. (2018) 8:5965. doi: 10.1038/s41598-018-24502-z

168. Staufert S, Torlakcik H, Pane S, Hierold C. Highly adherent parylene-c coatings with nanostructuring for enhanced cell adhesion and growth. IEEE Trans Nanobioscience. (2019) 18:230-3. doi: 10.1109/TNB.2019.2905498

169. Mather PT, Luo X, Rousseau IA. Shape memory polymer research. Annu Rev Mater Res. (2009) 39:445-71. doi: 10.1146/annurev-matsci-082908-145419

170. Lendlein A, Kelch S. Shape-memory polymers. Mater Today. (2007) 10:208. doi: 10.1016/S1369-7021(07)70047-0

171. Xie T. Recent advances in polymer shape memory. Polymer. (2011) 52:49855000. doi: 10.1016/j.polymer.2011.08.003

172. Lendlein A, Langer R. Biodegradable, elastic shapememory polymers for potential biomedical applications. Science. (2002) 296:1673-6. doi: 10.1126/science.106 6102

173. Feninat, EF, Laroche G, Fiset M, Mantovani D. Shape memory materials for biomedical applications. Adv Eng Mater. (2002) 4:91104. doi: 10.1002/1527-2648(200203)4:3<91::AID-ADEM91>3.0.CO;2-B

174. Liu C, Qin H, Mather PT. Review of progress in shape-memory polymers. J Mater Chem. (2007) 17:1543-58. doi: 10.1039/b615954k

175. Serrano MC, Ameer GA. Recent insights into the biomedical applications of shape-memory polymers. Macromol Biosci. (2012) 12:1156-71. doi: 10.1002/mabi.201200097

176. Small W, Singhal P, Wilson TS, Maitland DJ. Biomedical applications of thermally activated shape memory polymers. J Mater Chem. (2010) 20:335666. doi: 10.1039/b923717h

177. Zhao W, Liu L, Zhang F, Leng J, Liu Y. Shape memory polymers and their composites in biomedical applications. Mater Sci Eng C. (2019) 97:86483. doi: 10.1016/j.msec.2018.12.054

178. Ware T, Simon D, Liu C, Musa T, Vasudevan S, Sloan A, et al. Thiolene/acrylate substrates for softening intracortical electrodes. J Biomed Mater Res. (2013) 102:1-11. doi: 10.1002/jbmb.32946

179. Simon DM, Charkhkar H, St. John C, Rajendran S, Kang T, Reit R, et al. Design and demonstration of an intracortical probe technology with tunable modulus. J Biomed Mater Res Part A. (2017) 105:15968. doi: 10.1002/jbm.a.35896

180. Black BJ, Ecker M, Stiller A, Rihani R, Danda VR, Reed I, et al. In vitro compatibility testing of thiol-ene/acrylate-based shape memory polymers for use in implantable neural interfaces. J Biomed Mater Res Part A. (2018) 106:2891-8. doi: 10.1002/jbm.a.36478

181. Garcia-Sandoval A, Pal A, Mishra AM, Sherman S, Parikh AR, Joshi-Imre A, et al. Chronic softening spinal cord stimulation arrays. J Neural Eng. (2018) 15:045002. doi: 10.1088/1741-2552/aab90d

182. Wang J, Zhao Q, Wang Y, Zeng Q, Wu T, Du X. Self-unfolding flexible microelectrode arrays based on shape memory polymers. Adv Mater Technol. (2019) 4:1900566. doi: 10.1002/admt.201900566

183. Zhang Y, Zheng N, Ma Y, Xie T, Feng X. Bio-inspired 3D neural electrodes for the peripheral nerves stimulation using shape memory polymers. In: Technical Digest - International Electron Devices Meeting. San Francisco, CA (2019). doi: 10.1109/IEDM.2018.8614522

184. Zhang Y, Zheng N, Cao Y, Wang F, Wang P, Ma Y, et al. Climbing-inspired twining electrodes using shape memory for peripheral nerve stimulation 
and recording. Sci Adv. (2019) 5:eaaw1066. doi: 10.1126/sciadv.aa w1066

185. Ecker M, Joshi-Imre A, Modi R, Frewin CL, Garcia-Sandoval A, Maeng J, et al. From softening polymers to multimaterial based bioelectronic devices. Multifunct Mater. (2019) 2:012001. doi: 10.1088/2399-7532/aaed58

186. Rockwood DN, Preda RC, Yücel T, Wang X, Lovett ML, Kaplan DL. Materials fabrication from Bombyx mori silk fibroin. Nat Protoc. (2011) 6:1612-31. doi: 10.1038/nprot.2011.379

187. Zhang H, Magoshi J, Becker M, Chen JY, Matsunaga R. Thermal properties of Bombyx mori silk fibers. J Appl Polym Sci. (2002) 86:181720. doi: 10.1002/app.11089

188. Vepari C, Kaplan DL. Silk as a biomaterial. Prog Polym Sci. (2009) 32:9911007. doi: 10.1016/j.progpolymsci.2007.05.013

189. Lawrence BD, Marchant JK, Pindrus MA, Omenetto FG, Kaplan DL. Silk film biomaterials for cornea tissue engineering. Biomaterials. (2009) 30:1299308. doi: 10.1016/j.biomaterials.2008.11.018

190. Horan RL, Antle K, Collette AL, Wang Y, Huang J, Moreau JE, et al. In vitro degradation of silk fibroin. Biomaterials. (2005) 26:338593. doi: 10.1016/j.biomaterials.2004.09.020

191. Li X, Shi W, Yu X, Yu J. Performance improvement of organic fieldeffect transistor based nitrogen dioxide gas sensor using biocompatible PMMA/silk fibroin bilayer dielectric. J Mater Sci Mater Electron. (2015) 26:7948-54. doi: 10.1007/s10854-015-3448-7

192. Wang $\mathrm{CH}$, Hsieh CY, Hwang JC. Flexible organic thin-film transistors with silk fibroin as the gate dielectric. Adv Mater. (2011) 23:16304. doi: 10.1002/adma.201004071

193. Li HQ, Yu JS, Huang W, Shi W, Huang J. High performance pentacene organic field-effect transistors consisting of biocompatible PMMA/silk fibroin bilayer dielectric. Chin Phys B. (2014) 23:8-12. doi: 10.1088/1674-1056/23/3/038505

194. Zhu B, Wang H, Leow WR, Cai Y, Loh XJ, Han MY, et al. Silk fibroin for flexible electronic devices. Adv Mater. (2016) 28:425065. doi: 10.1002/adma.201504276

195. Shivananda CS, Lakshmeesha R, Sangappa B. Structural, thermal and electrical properties of silk fibroin-silver nanoparticles composite films. $J$ Mater Sci Mater Electron. (2019) 31:41-51. doi: 10.1007/s10854-019-00786-3

196. Cao Y, Wang B. Biodegradation of silk biomaterials. Int J Mol Sci. (2009) 10:1514-24. doi: 10.3390/ijms10041514

197. Gil ES, Park SH, Hu X, Cebe P, Kaplan DL. Impact of sterilization on the enzymatic degradation and mechanical properties of silk biomaterials. Macromol Biosci. (2014) 14:257-69. doi: 10.1002/mabi.201300321

198. You R, Xu Y, Liu G, Liu Y, Li X, Li M. Regulating the degradation rate of silk fibroin films through changing the genipin crosslinking degree. Polym Degrad Stab. (2014) 109:226-32. doi: 10.1016/j.polymdegradstab.2014.07.029

199. Liu B, Song YW, Jin L, Wang ZJ, Pu DY, Lin SQ, et al. Silk structure and degradation. Colloids Surfaces B Biointerfaces. (2015) 131:1228. doi: 10.1016/j.colsurfb.2015.04.040

200. You R, Xu Y, Liu Y, Li X, Li M. Comparison of the in vitro and in vivo degradations of silk fibroin scaffolds from mulberry and nonmulberry silkworms. Biomed Mater. (2015) 10:015003. doi: 10.1088/1748-6041/10/1/015003

201. Kim DH, Viventi J, Amsden JJ, Xiao J, Vigeland L, Kim YS, et al. Erratum: Dissolvable films of silk fibroin for ultrathin conformal bio-integrated electronics. Nat Mater. (2010) 9:511-7. doi: 10.1038/nmat2745

202. Wu F, Tien LW, Chen F, Berke JD, Kaplan DL, Yoon E. Silk-backed structural optimization of high-density flexible intracortical neural probes. J Microelectromech Syst. (2015) 24:62-9. doi: 10.1109/JMEMS.2014.2375326

203. Hronik-Tupaj M, Raja WK, Tang-Schomer M, Omenetto FG, Kaplan DL. Neural responses to electrical stimulation on patterned silk films. J Biomed Mater Res. (2013) 71:233-6. doi: 10.1002/jbm.a.34565

204. Maya-Vetencourt JF, Ghezzi D, Antognazza MR, Colombo E, Mete M, Feyen $\mathrm{P}$, et al. A fully organic retinal prosthesis restores vision in a rat model of degenerative blindness. Nat Mater. (2017) 16:681-9. doi: 10.1038/nmat4874

205. Watanabe S, Takahashi H, Torimitsu K. Electroconductive polymer-coated silk fiber electrodes for neural recording and stimulation in vivo. Jpn J Appl Phys. (2017) 56:037001. doi: 10.7567/JJAP.56.037001

206. Heo YS, Cabrera LM, Song JW, Futai N, Tung YC, Smith GD, et al. Characterization and resolution of evaporation-mediated osmolality shifts that constrain microfluidic cell culture in poly(dimethylsiloxane) devices. Anal Chem. (2007) 79:1126-34. doi: 10.1021/ac061990v

207. Nusil Technology LLC. Implant Line Product Guide. (2017). Available online at: https://www.avantorsciences.com/pages/en/medical-implants\# (accessed April 5, 2021).

208. Corporation DC. Silastic MDX4-4210 biomedical grade elastomer. Build Res. (1991) 19:143-5.

209. Roussel M, Malhaire C, Deman AL, Chateaux JF, Petit L, Seveyrat L, et al. Electromechanical study of polyurethane films with carbon black nanoparticles for MEMS actuators. J Micromech Microeng. (2014) 24:055011. doi: 10.1088/0960-1317/24/5/055011

210. Rezaei F, Sharif F, Sarabi AA, Kasiriha SM, Rahmanian M, Akbarinezhad E. Evaluating water transport through high solid polyurethane coating using the EIS method. J Coat Technol Res. (2010) 7:209-17. doi: 10.1007/s11998-009-9173-5

211. Lifesciences Lubrizol. Pellethane 2363-80AE TPU. Available online at: https://www.lubrizol.com/Health/Medical/Polymers/Pellethane-TPU (accessed May 3, 2021).

212. 3M. Polyurethane film 9832F. (2010). Available online at: https://www.3m. com/3M/en_US/p/d/v000266868/ (accessed May 3, 2021).

213. Lawrence BD, Wharram S, Kluge JA, Leisk GG, Omenetto FG, Rosenblatt MI, et al. Effect of hydration on silk film material properties. Macromol Biosci. (2010) 10:393-403. doi: 10.1002/mabi.200900294

214. Seo J, Lee A, Oh J, Han H. Effects of diamines (1,4-phenylene diamine and $4,4^{\prime}$-oxydianiline) on water sorption behavior of polyimide thin film. Polym J. (2000) 32:583-8. doi: 10.1295/polymj.32.583

215. The complete guide to parylene coatings, Parylene VSI.ç Available at: www.vsiparylene.com

216. Aregueta-Robles UA, Woolley AJ, Poole-Warren LA, Lovell NH, Green RA. Organic electrode coatings for next-generation neural interfaces. Front Neuroeng. (2014) 7:15. doi: 10.3389/fneng.2014.00015

217. Gabay T, Ben-David M, Kalifa I, Sorkin R, Abrams ZR, Ben-Jacob E, et al. Electro-chemical and biological properties of carbon nanotube based multi-electrode arrays. Nanotechnology. (2007) 18:035201. doi: 10.1088/0957-4484/18/3/03 5201

218. Park HC, Champakalakshmi R, Panengad PP, Raghunath M, Mehta JS. Tissue adhesives in ocular surgery. Exp Rev Ophthalmol. (2011) 6:63155. doi: 10.1586/eop.11.64

219. Lima LH, Morales Y, Cabral T. Ocular Biocompatibility of Poly-N-Isopropylacrylamide (pNIPAM). J Ophthalmol. (2016) 2016:5356371. doi: 10.1155/2016/5356371

220. Capella V, Rivero RE, Liaudat AC, Ibarra LE, Roma DA, Alustiza F, et al. Cytotoxicity and bioadhesive properties of poly- $\mathrm{N}$-isopropylacrylamide hydrogel. Heliyon. (2019) 5:e01474. doi: 10.1016/j.heliyon.2019.e01474

221. Cheng X, Wang Y, Hanein Y, Böhringer KF, Ratner BD. Novel cell patterning using microheater-controlled thermoresponsive plasma films. J Biomed Mater Res. (2004) 70:159-68. doi: 10.1002/jbm.a.30053

222. Cooperstein MA, Canavan HE. Assessment of cytotoxicity of $(\mathrm{N}$ isopropyl acrylamide) and poly( $\mathrm{N}$-isopropyl acrylamide)-coated surfaces. Biointerphases. (2013) 8:19. doi: 10.1186/1559-4106-8-19

223. Lima LH, Morales Y, Cabral T. Poly-N-isopropylacrylamide (pNIPAM): A reversible bioadhesive for sclerotomy closure. Int J Retin Vitr. (2016) 2:23. doi: 10.1186/s40942-016-0048-5

224. Tunc M, Humayun $M$, Cheng $\mathrm{X}$, Ratner BD. A reversible thermosensitive adhesive for retinal implants: In vivo experience with plasma-deposited poly(N-isopropyl acrylamide). Retina. (2008) 28:1338-43. doi: 10.1097/IAE.0b013e31817b6b42

225. Littlechild SL, Brummer G, Zhang Y, Conrad GW. Fibrinogen, riboflavin, and UVA to immobilize a corneal flap-conditions for tissue adhesion. Investig Ophthalmol Vis Sci. (2012) 53:4011-20. doi: 10.1167/iovs.12-9515

226. Seifert J, Hammer CM, Rheinlaender J, Sel S, Scholz M, Paulsen F, et al. Distribution of young's modulus in porcine corneas after riboflavin/UVAinduced collagen cross-linking as measured by atomic force microscopy. PLoS ONE. (2014) 9:e88186. doi: 10.1371/journal.pone.0088186

227. Balkenende DWR, Winkler SM, Messersmith PB. Marineinspired polymers in medical adhesion. Eur Polym J. (2019) 116:134-43. doi: 10.1016/j.eurpolymj.2019.03.059 
228. Moulay S. Dopa/catechol-tethered polymers: dioadhesives and biomimetic adhesive materials. Polym Rev. (2014) 54:436513. doi: $10.1080 / 15583724.2014 .881373$

229. Hofman AH, van Hees IA, Yang J, Kamperman M. Bioinspired underwater adhesives by using the supramolecular toolbox. Adv Mater. (2018) 30:1704640. doi: 10.1002/adma.201704640

230. Tucker CL, Jones JA, Bringhurst HN, Copeland CG, Addison JB, Weber WS, et al. Mechanical and physical properties of recombinant spider silk films using organic and aqueous solvents. Biomacromolecules. (2014) 15:315870. doi: $10.1021 / \mathrm{bm} 5007823$

231. Sahni V, Blackledge TA, Dhinojwala A. A review on spider silk adhesion. $J$ Adhes. (2011) 87:595-614. doi: 10.1080/00218464.2011.583588

232. Tokareva O, Michalczechen-Lacerda VA, Rech EL, Kaplan DL. Recombinant DNA production of spider silk proteins. Microb Biotechnol. (2013) 6:65163. doi: 10.1111/1751-7915.12081

233. Amarpuri G, Zhang C, Diaz C, Opell BD, Blackledge TA, Dhinojwala A. Spiders tune glue viscosity to maximize adhesion. ACS Nano. (2015) 9:11472-8. doi: 10.1021/acsnano.5b05658

234. Jones JA, Harris TI, Tucker CL, Berg KR, Christy SY, Day BA, et al. More than just fibers: an aqueous method for the production of innovative recombinant spider silk protein materials. Biomacromolecules. (2015) 16:1418-25. doi: 10.1021/acs.biomac.5b00226

235. Boateng SY, Lateef SS, Mosley W, Hartman TJ, Hanley L, Russell B. RGD and YIGSR synthetic peptides facilitate cellular adhesion identical to that of laminin and fibronectin but alter the physiology of neonatal cardiac myocytes. Am J Physiol Physiol. (2004) 288:C308. doi: 10.1152/ajpcell.00199.2004

236. Huettner N, Dargaville TR, Forget A. Discovering cell-adhesion peptides in tissue engineering: beyond RGD. Trends Biotechnol. (2018) 36:37283. doi: 10.1016/j.tibtech.2018.01.008

237. Zhao Z, Li X, He F, Wei X, Lin S, Xie C. Parallel, minimally-invasive implantation of ultra-flexible neural electrode arrays. J Neural Eng. (2019) 16:035001. doi: 10.1088/1741-2552/ab05b6

238. Joo HR, Lan Fan J, Chen S, Pebbles JA, Liang H, Chung JE, et al. A microfabricated, 3D-sharpened silicon shuttle for insertion of flexible electrode arrays through dura mater into brain. J Neural Eng. (2019) 16:066021. doi: 10.1088/1741-2552/ab2b2e

239. Apollo NV, Murphy B, Prezelski K, Driscoll N, Richardson AG, Lucas TH, et al. Gels, jets, mosquitoes, and magnets: a review of implantation strategies for soft neural probes. J Neural Eng. (2020) 17:041002. doi: 10.1088/1741-2552/abacd7

240. Ansaldo A, Castagnola E, Maggiolini E, Fadiga L, Ricci D. Superior electrochemical performance of carbon nanotubes directly grown on sharp microelectrodes. ACS Nano. (2011) 5:2206-14. doi: 10.1021/nn103445d

241. Baldrighi M, Trusel M, Tonini R, Giordani S. Carbon nanomaterials interfacing with neurons: an in vivo perspective. Front Neurosci. (2016) 10:250. doi: 10.3389/fnins.2016.00250

242. Veronica A, Li Y, Hsing I. Minimally invasive \& long-lasting neural probes from a materials perspective. Electroanalysis. (2019) 31:586602. doi: 10.1002/elan.201800719

243. Wang K, Fishman HA, Dai H, Harris JS. Neural stimulation with a carbon nanotube microelectrode array. Nano Lett. (2006) 6:20438. doi: 10.1021/nl061241t

244. Rastogi SK, Kalmykov A, Johnson N, Cohen-Karni T. Bioelectronics with nanocarbons. J Mater Chem B. (2018) 6:7159-78. doi: 10.1039/C8TB01600C

245. Kim $T$, Cho $M$, Yu KJ. Flexible and stretchable bio-integrated electronics based on carbon nanotube and graphene. Materials. (2018) 11:1163. doi: 10.3390/ma11071163

246. Fuchsberger K, Goff A, Le Gambazzi L, Toma FM, Goldoni A, Giugliano $M$, et al. Multiwalled carbon-nanotube-functionalized microelectrode arrays fabricated by microcontact printing: platform for studying chemical and electrical neuronal signaling. Small. (2011) 7:524-30. doi: 10.1002/smll.201001640

247. Heo DN, Kim HJ, Lee YJ, Heo M, Lee SJ, Lee D, et al. Flexible and Highly Biocompatible Nanofiber-Based Electrodes for Neural Surface Interfacing. ACS Nano. (2017) 11:2961-71. doi: 10.1021/acsnano.6b08390

248. Carli S, Lambertini L, Zucchini E, Ciarpella F, Scarpellini A, Prato $M$, et al. Single walled carbon nanohorns composite for neural sensing and stimulation. Sensors Actuat B Chem. (2018) 271:280-8. doi: 10.1016/j.snb.2018.05.083
249. Lovat V, Pantarotto D, Lagostena L, Cacciari B, Grandolfo M, Righi M, et al. Carbon nanotube substrates boost neuronal electrical signaling. Nano Lett. (2005) 5:1107-10. doi: 10.1021/nl050637m

250. Fabbro A, Villari A, Laishram J, Scaini D, Toma FM, Turco A, et al. Spinal cord explants use carbon nanotube interfaces to enhance neurite outgrowth and to fortify synaptic inputs. ACS Nano. (2012) 6:204155. doi: $10.1021 / \mathrm{nn} 203519 \mathrm{r}$

251. Ben-Jacob E, Hanein Y. Carbon nanotube micro-electrodes for neuronal interfacing. J Mater Chem. (2008) 18:5181-6. doi: 10.1039/b805878b

252. Shoval A. Carbon nanotube electrodes for effective interfacing with retinal tissue. Front Neuroeng. (2009) 2:2009. doi: 10.3389/neuro.16.004.2009

253. Mazzatenta A, Giugliano M, Campidelli S, Gambazzi L, Businaro L, Markram $\mathrm{H}$, et al. Interfacing neurons with carbon nanotubes: electrical signal transfer and synaptic stimulation in cultured brain circuits. J Neurosci. (2007) 27:6931-6. doi: 10.1523/JNEUROSCI.1051-07.2007

254. Vitale F, Summerson SR, Aazhang B, Kemere C, Pasquali M. Neural stimulation and recording with bidirectional, soft carbon nanotube fiber microelectrodes. ACS Nano. (2015) 9:4465-74. doi: 10.1021/acsnano.5b01060

255. Gheith MK, Sinani VA, Wicksted JP, Matts RL, Kotov NA. Single-walled carbon nanotube polyelectrolyte multilayers and freestanding films as a biocompatible platform for neuroprosthetic implants. Adv Mater. (2005) 17:2663-70. doi: 10.1002/adma.200500366

256. Yi W, Chen C, Feng Z, Xu Y, Zhou C, Masurkar N, et al. A flexible and implantable microelectrode arrays using high-temperature grown vertical carbon nanotubes and a biocompatible polymer substrate. Nanotechnology. (2015) 26:125301. doi: 10.1088/0957-4484/26/12/125301

257. Yu Z, McKnight TE, Ericson MN, Melechko AV, Simpson ML, Morrison B. Vertically aligned carbon nanofiber arrays record electrophysiological signals from hippocampal slices. Nano Lett. (2007) 7:2188-95. doi: 10.1021/nl070291a

258. de Asis ED, Nguyen-Vu TDB, Arumugam PU, Chen H, Cassell AM, Andrews RJ, et al. High efficient electrical stimulation of hippocampal slices with vertically aligned carbon nanofiber microbrush array. Biomed Microdev. (2009) 11:801-8. doi: 10.1007/s10544-009-9295-7

259. David-Pur M, Bareket-Keren L, Beit-Yaakov G, Raz-Prag D, Rand D, Hanein Y. Carbon-nanotube based flexible electrodes for retinal recording and stimulation. Proc IEEE Sensors. (2013) 2013:1-4. doi: 10.1109/ICSENS.2013.6688452

260. Bareket L, Waiskopf N, Rand D, Lubin G, David-Pur M, Ben-Dov J, et al. Semiconductor nanorod-carbon nanotube biomimetic films for wire-free photostimulation of blind retinas. Nano Lett. (2014) 14:668592. doi: $10.1021 / \mathrm{nl} 5034304$

261. Lee S, Ozlu B, Eom T, Martin DC, Shim BS. Electrically conducting polymers for bio-interfacing electronics: From neural and cardiac interfaces to bone and artificial tissue biomaterials. Biosens Bioelectron. (2020) 170:112620. doi: 10.1016/j.bios.2020.112620

262. Shi Y, Liu R, He L, Feng H, Li Y, Li Z. Recent development of implantable and flexible nerve electrodes. Smart Mater Med. (2020) 1:13147. doi: 10.1016/j.smaim.2020.08.002

263. Green RA. Conducting polymers for neural prosthetic and neural interface applications. Adv Mater. (2015) 27:7620-37. doi: 10.1002/adma.201501810

264. Vara H, Collazos-Castro JE. Enhanced spinal cord microstimulation using conducting polymer-coated carbon microfibers. Acta Biomater. (2019) 90:71-86. doi: 10.1016/j.actbio.2019.03.037

265. Tomczykowa M, Plonska-Brzezinska ME. Conducting polymers, hydrogels and their composites: Preparation, properties and bioapplications. Polymers. (2019) 11:350. doi: 10.3390/polym11020350

266. Fang Y, Meng L, Prominski A, Schaumann EN, Seebald M, Tian B. Recent advances in bioelectronics chemistry. Chem Soc Rev. (2020) 49:79788035. doi: 10.1039/D0CS00333F

267. Fu F, Wang J, Zeng H, Yu J. Functional conductive hydrogels for bioelectronics. ACS Mater Lett. (2020) 2:1287301. doi: 10.1021/acsmaterialslett.0c00309

268. Du ZJ, Kolarcik CL, Kozai TDY, Luebben SD, Sapp SA, Zheng XS, et al. Ultrasoft microwire neural electrodes improve chronic tissue integration. Acta Biomater. (2017) 53:46-58. doi: 10.1016/j.actbio.2017.02.010

269. Zheng X, Woeppel KM, Griffith AY, Chang E, Looker MJ, Fisher LE, et al. Soft conducting elastomer for peripheral nerve interface. Adv Healthc Mater. (2019) 8:1801311. doi: 10.1002/adhm.201801311 
270. Ferrari LM, Rodríguez-Meana B, Bonisoli A, Cutrone A, Micera S, Navarro $\mathrm{X}$, et al. All-polymer printed low-cost regenerative nerve cuff electrodes. Front Bioeng Biotechnol. (2021) 9:29. doi: 10.3389/fbioe.2021.615218

271. Yuk H, Lu B, Lin S, Qu K, Xu J, Luo J, et al. 3D printing of conducting polymers. Nat Commun. (2020) 11:4-11. doi: 10.1038/s41467-020-15316-7

272. Roska B, Pepperberg D. Restoring vision to the Blind DOI. The Lasker/IRRF initiative for innovation in vision science. Transl Vis Sci Technol. (2014) 3:13-22. doi: 10.1167/tvst.3.7.1

273. Bareket-Keren L, Hanein Y. Novel interfaces for light directed neuronal stimulation: advances and challenges. Int J Nanomed. (2014) 9:6583. doi: $10.2147 /$ IJN.S51193

274. Wang Y, Guo L. Nanomaterial-enabled neural stimulation. Front Neurosci. (2016) 10:69. doi: 10.3389/fnins.2016.00069

275. Goncalves SB, Ribeiro JF, Silva AF, Costa RM, Correia JH. Design and manufacturing challenges of optogenetic neural interfaces: a review. J Neural Eng. (2017) 14:041001. doi: 10.1088/1741-2552/aa7004

276. Pappas TC, Wickramanyake WMS, Jan E, Motamedi M, Brodwick M, Kotov NA. Nanoscale engineering of a cellular interface with semiconductor nanoparticle films for photoelectric stimulation of neurons. Nano Lett. (2007) 7:513-9. doi: 10.1021/nl062513v

277. Winter JO, Gomez N, Korgel BA, Schmidt CE. Quantum dots for electrical stimulation of neural cells. Nanobiophotonics Biomed Appl. (2005) 5705:235. doi: 10.1117/12.602363

278. Zhao Y, Larimer P, Pressler RT, Strowbridge BW, Burda C. Wireless activation of neurons in brain slices using nanostructured semiconductor photoelectrodes. Angew Chem Int Ed Engl. (2009) 48:2407-10. doi: 10.1002/anie.200806093

279. Benfenati V, Martino N, Antognazza MR, Pistone A, Toffanin S, Ferroni S, et al. Photostimulation of whole-cell conductance in primary rat neocortical astrocytes mediated by organic semiconducting thin films. Adv Healthc Mater. (2014) 3:392-9. doi: 10.1002/adhm.201300179

280. Rand D, Jakešová M, Lubin G, Vebraite I, David-Pur M, Derek V, et al. Direct electrical neurostimulation with organic pigment photocapacitors. Adv Mater. (2018) 30:1707292. doi: 10.1002/adma.201707292

281. Vebraite I. Fabrication and characterization of nanostructured bioelectrodes (Master's thesis), Hebrew University of Jerusalem, Rehovot.

282. Głowacki ED, Voss G, Sariciftci NS. 25th anniversary article: Progress in chemistry and applications of functional indigos for organic electronics. $A d v$ Mater. (2013) 25:6783-800. doi: 10.1002/adma.201302652

283. Silverå-Ejneby $M$, Jakešová $M$, Jose FJ, Migliaccio L, Zhao Z, Berggren M, et al. A chronic photocapacitor implant for noninvasive neurostimulation with deep red light. bioRxiv. (2020). doi: 10.1101/2020.07.01.182113

284. Zhang $M$, Wang $\mathrm{X}$, Huang $\mathrm{Z}$, Rao W. Liquid metal based flexible and implantable biosensors. Biosensors. (2020) 10:170. doi: 10.3390/bios10110170

285. Yi L, Liu J. Liquid metal biomaterials: a newly emerging area to tackle modern biomedical challenges. Int Mater Rev. (2017) 62:41540. doi: 10.1080/09506608.2016.1271090

286. Wang X, Ren Y, Liu J. Liquid metal enabled electrobiology: A new frontier to tackle disease challenges. Micromachines. (2018) 9:360. doi: 10.3390/mi9070360

287. Dickey MD. Stretchable and soft electronics using liquid metals. Adv Mater. (2017) 29:1606425. doi: 10.1002/adma.201606425

288. Guo R, Liu J. Implantable liquid metal-based flexible neural microelectrode array and its application in recovering animal locomotion functions. $J$ Micromech Microeng. (2017) 27:104002. doi: 10.1088/1361-6439/aa891c

289. Schiavone G, Wagner F, Fallegger F, Kang X, Vachicouras N, Barra B, et al. Long-term functionality of a soft electrode array for epidural spinal cord stimulation in a minipig model. In: Proc. Annu. Int. Conf. IEEE Eng. Med. Biol. Soc. Honolulu, HI (2018) 1432-1435. doi: 10.1109/EMBC.2018.8512584

290. Airaghi Leccardi MJI, Chenais NAL, Ferlauto L, Kawecki M, Zollinger EG, Ghezzi D. Photovoltaic organic interface for neuronal stimulation in the near-infrared. Commun Mater. (2020) 1:21. doi: 10.1038/s43246-020-0023-4

291. Keserü M, Feucht M, Bornfeld N, Laube T, Walter P, Rössler G, et al. Acute electrical stimulation of the human retina with an epiretinal electrode array. Acta Ophthalmol. (2012) 90:e1-8. doi: 10.1111/j.1755-3768.2011.02288.x
292. Jiang X, Sui X, Lu Y, Yan Y, Zhou C, Li L, et al. In vitro and in vivo evaluation of a photosensitive polyimide thin-film microelectrode array suitable for epiretinal stimulation. J Neuroeng Rehabil. (2013) 10:28. doi: 10.1186/1743-0003-10-48

293. Matet A, Amar N, Mohand-Said S, Sahel JA, Barale O. Argus II retinal prosthesis implantation with scleral flap and autogenous temporalis fascia as alternative patch graft material: a 4-year follow-up. Clin Ophthalmol. (2016) 10:1565-71. doi: 10.2147/OPTH.S112403

294. Finn AP, Grewal DS, Vajzovic L. Argus II retinal prosthesis system: A review of patient selection criteria, surgical considerations, post-operative outcomes. Clin Ophthalmol. (2018) 12:1089-97. doi: 10.2147/OPTH.S137525

295. Lin TC, Wang LC, Yue L, Zhang Y, Falabella P, Zhu D, et al. Histopathologic assessment of optic nerves and retina from a patient with chronically implanted argus II retinal prosthesis system. Transl Vis Sci Technol. (2019) 8:31. doi: 10.1167/tvst.8.3.31

296. Kim JH, Lee GH, Kim S, Chung HW, Lee JH, Lee SM, et al. Flexible deep brain neural probe for localized stimulation and detection with metal guide. Biosens Bioelectron. (2018) 117:436-43. doi: 10.1016/j.bios.2018.06.035

297. Shon A, Chu JU, Jung J, Kim H, Youn I. An implantablewireless neural interface system for simultaneous recording and stimulation of peripheral nerve with a single cuff electrode. Sensors. (2018) 18:1. doi: 10.3390/s18010001

298. Xue N, Martinez ID, Sun J, Cheng Y, Liu C. Flexible multichannel vagus nerve electrode for stimulation and recording for heart failure treatment. Biosens Bioelectron. (2018) 112:114-9. doi: 10.1016/j.bios.2018.04.043

299. Edwards CA, Kouzani A, Lee KH, Ross EK. Neurostimulation devices for the treatment of neurologic disorders. Mayo Clin Proc. (2017) 92:142744. doi: 10.1016/j.mayocp.2017.05.005

300. Reddy S, He L, Ramakrishana S. Miniaturized-electroneurostimulators and self-powered/rechargeable implanted devices for electricalstimulation therapy. Biomed Signal Process Control. (2018) 41:255-63. doi: 10.1016/j.bspc.2017.11.018

301. Stieglitz T. Why neurotechnologies? About the purposes, opportunities and limitations of neurotechnologies in clinical applications. neuroethics. Neuroethics. (2019) 14:5-16. doi: 10.1007/s12152-019-09406-7

302. Edward ES, Kouzani AZ, Tye SJ. Towards miniaturized closedloop optogenetic stimulation devices. J Neural Eng. (2018) 15:021002. doi: 10.1088/1741-2552/aa7d62

303. Manzouri F, Schulze-Bonhage A, Dümpelmann M, Heller S, Woias P. Optimized detector for closed-loop devices for neurostimulation. In: 2017 IEEE International Conference on Systems, Man, and Cybernetics, SMC. Banff, AB (2017). doi: 10.1109/SMC.2017.8122939

304. Elyahoodayan S, Member S, Berger TW, Song D. A closed - loop multi - channel asynchronous neurostimulator to mimic neural code for cognitive prosthesis. In: 40th Annual International Conference of the IEEE Engineering in Medicine and Biology Society (EMBC). Honolulu, HI (2018). doi: 10.1109/EMBC.2018.8512497

305. Iturrate I, Pereira M, Millán J, del R. Closed-loop electrical neurostimulation: challenges and opportunities. Curr Opin Biomed Eng. (2018) 8:28-37. doi: 10.1016/j.cobme.2018. 09.007

306. Zhou A, Johnson BC, Muller R. Toward true closed-loop neuromodulation: artifact-free recording during stimulation. Curr Opin Neurobiol. (2018) 50:119-27. doi: 10.1016/j.conb.2018. 01.012

Conflict of Interest: The authors declare that the research was conducted in the absence of any commercial or financial relationships that could be construed as a potential conflict of interest.

Copyright (c) 2021 Vébraite and Hanein. This is an open-access article distributed under the terms of the Creative Commons Attribution License (CC BY). The use, distribution or reproduction in other forums is permitted, provided the original author(s) and the copyright owner(s) are credited and that the original publication in this journal is cited, in accordance with accepted academic practice. No use, distribution or reproduction is permitted which does not comply with these terms. 